\title{
R\&D SUBSIDIES AND CLIMATE POLICY: IS THERE A "FREE LUNCH"?
}

\author{
DAVID POPP \\ Department of Public Administration, Center for Environmental Policy Administration, Center for \\ Technology and Information Policy, The Maxwell School, Syracuse University, 400 Eggers Hall, \\ Syracuse, NY 13244-1090; Faculty Research Fellow, National Bureau of Economic Research, \\ Cambridge, MA 02138 \\ E-mail:dcpopp@maxwell.syr.edu
}

\begin{abstract}
Because of the long-term nature of the climate problem, technological advances are often seen as an important component of any solution. However, when considering the potential for technology to help solve the climate problem, two market failures exist which lead to underinvestment in climate-friendly R\&D: environmental externalities and the public goods nature of new knowledge. As a result, government subsidies to climate-friendly $R \& D$ projects are often proposed as part of a policy solution. Using the ENTICE model, I analyze the effectiveness of such subsidies, both with and without other climate policies, such as a carbon tax. While R\&D subsidies do lead to significant increases in climate-friendly $R \& D$, this $R \& D$ has little impact on the climate itself. Subsidies address the problem of knowledge as a public good, but they do not address the environmental externality, and thus offer no additional incentive to adopt new technologies. Moreover, high opportunity costs to R\&D limit the potential role that subsidies can play. While R\&D subsidies can improve efficiency, policies that directly affect the environmental externality have a much larger impact on both atmospheric temperature and economic welfare.
\end{abstract}

Politicians often propose increased research and development (R\&D) spending as a solution to the climate change problem. Such spending offers the political cover of doing "something" about climate change while avoiding more painful costs that may come from regulations requiring emissions reductions. For example, in his 2003 State of the Union address, President George W. Bush proposed \$1.2 billion of research funding to develop vehicles powered by fuel cells. In 1999, the President's Committee of Advisors on Science and Technology (PCAST) recommended increasing the U.S. energy R\&D budget by $\$ 500$ million in 2005 to address the need for clean energy sources. Can such policies impact the global climate? Can R\&D subsidies substitute for more restrictive emissions policies? This paper addresses these questions.

Because of the long-term nature of the climate change problem, technological change is often considered a part of any policy solution. There is ample evidence that market forces such as higher prices or stringent environmental policies induce technological change. For example, Popp (2002) documents dramatic increases in patenting for renewable energy technologies during the energy crisis of the 1970s. In recent years, economic models of climate policy have paid increasing attention to the links between policy and technological change. Models that 
explicitly link technological progress to climate policy find that such links reduce the costs of a given policy, as policy levers serve to hasten the development of more climate-friendly technologies.

Given the importance of policy-induced technological change, as well as a political climate that favors R\&D subsidies over policies to limit emissions, it is useful to consider the role that R\&D policy, by itself, might play. Such policies are of interest because, in the language of economists, markets for new knowledge are imperfect. Spillovers of knowledge make it difficult for inventors to reap the full social benefits of their innovations. As such, the incentives provided by private markets for $\mathrm{R} \& \mathrm{D}$ investment lead to underinvenstment in R\&D. Policies addressing this, such as government-funded subsidies for $R \& D, R \& D$ tax credits, or improved intellectual property rights to help inventors capture more of the returns to innovation, lead to greater levels of R\&D spending, and presumably more innovation as a result.

Recent work in the field of economics to consider the role of R\&D policy as part of a climate policy portfolio includes Schneider and Goulder (1997), Kverndokk et al. (2004), and Fischer and Newell (2004). Schneider and Goulder (1997) note that even if it is desirable to postpone the bulk of emissions abatement to the future (see, for example, Wigley et al., 1996), short-term policies that bring about low-cost emissions reductions are desirable. One reason for this argument is that such policies spur innovation, making future emissions abatement less costly. However, they also find that simply using R\&D subsidies to achieve these cost reductions is not as effective. While $R \& D$ subsidies do correct market failures that pertain to knowledge markets, they do not address environmental market failures, and thus do not encourage adoption of any newly discovered climate-friendly technologies. Kverndokk et al. (2004) extend this work by considering both an existing and potential new alternative energy technology. R\&D subsidies increase usage of the existing alternative energy technology, but as a result delay the introduction of the newer, and possibly better, technology. Fischer and Newell (2004) compare R\&D subsidies and other policies designed to reduce carbon emissions from the U.S. electricity sector. They rank R\&D subsidies as the least effective for reducing emissions, but do not consider the effect of knowledge spillovers, and do not consider the use of multiple policies simultaneously. Outside of economics, papers such as Caldeira et al. (2003) and Hoffert et al. (2002) emphasize the need for R\&D to increase the availability of carbon-free energy sources for long-term reductions.

This paper builds on this work to study the role of both carbon taxes and R\&D subsidies using the ENTICE model (Popp forthcoming, 2004), an extension of the well-known DICE model of global warming (Nordhaus, 1994; Nordhaus and Boyer, 2000). Like the DICE model, the ENTICE model is dynamic growth model linking economic activity and the environment. Because it explicitly models the economic impact of climate damages, the model can be used to simulate optimal policy paths that balance both the costs and benefits of climate policy. In this paper, I use the model to compare the effectiveness of R\&D subsidies to policies such as 
a carbon tax designed to reduce emissions. Because the ENTICE model calculates the costs and benefits of each policy, I am able to build on the existing literature by calculating optimal levels of R\&D subsidies. Like Schneider and Goulder, I show that these subsidies do enhance the effects of other policies, such as a carbon tax, but that R\&D subsidies have little impact on emissions or net economic welfare when not accompanied by policies designed to limit emissions. Furthermore, by examining the change in optimal policy paths with and without R\&D subsidies, I show that most of the benefits of R\&D subsidies come from cost savings, as there is little change in emissions under a carbon tax with or without subsidies in place. Finally, when deciding on a level of government R\&D spending, policymakers need to be aware of the opportunity costs of new R\&D spending. Because R\&D is performed by highly-trained personnel, some new energy R\&D will likely come at the cost of other types of productive R\&D. If policymakers ignore these costs and set $R \& D$ subsidies too high, the overall macroeconomic effect of subsidies may even be negative.

\section{Theory: Market Failures Affecting Environmental R\&D}

While market forces will lead firms to do some research on technologies designed to reduce carbon emissions, there are two reasons to expect markets to underinvest in such R\&D. These market failures provide the motivation for government policy designed to increase such research. One, of course, is the traditional problem of environmental externalities. Because carbon emissions are not priced by the market, firms and consumers have no incentive to reduce emissions without policy intervention. This reduces the market for technologies that reduce emissions, and thus reduces incentives to develop such technologies. ${ }^{1}$

The second market failure pertaining to R\&D is the public goods nature of knowledge (see, for example, Geroski, 1995). In most cases, new technologies must be made available to the public for the inventor to reap the rewards of invention. However, by making new inventions public, some (if not all) of the knowledge embodied in the invention becomes public knowledge. This public knowledge may lead to additional innovations, or even to copies of the current innovations. ${ }^{2}$ These knowledge spillovers provide benefit to the public as a whole, but not to the innovator. As a result, private firms do not have incentives to provide the socially optimal level of research activity.

Much economic research has been done quantifying the effect of such spillovers. Economists studying the returns to research consistently find that knowledge spillovers result in a wedge between private and social rates return to R\&D. Examples of such studies include Mansfield (1977, 1996), Pakes (1985), Jaffe (1986), Hall (1996), and Jones and Williams (1998). Typical results include marginal social rates of return between 30 and $50 \%$. In comparison, estimates of private marginal rates of return on investments range from 7 to 15\% (Bazelon and Smetters, 1999; 
Jones and Williams, 1998; Hall 1996). Since firms make investment decisions based on their private returns, the wedge between private and social rates of return suggests socially beneficial research opportunities are being ignored by firms because they are unable to fully capture the rewards of such innovations.

Because of knowledge spillovers, climate-friendly R\&D will be underprovided by market forces even if policies to correct the environmental externalities of emissions, such as carbon taxes, are in place. Popp (2004) finds that the welfare gains from an optimal carbon tax increase by seven percent when the tax is supplemented with R\&D subsidies sufficient to support all socially-efficient research. This suggests two possible avenues through which policy can encourage the development of environmentally-friendly technologies: correcting the environmental externality and/or correcting knowledge market failures.

Not surprisingly, economic theory dictates that the socially optimal policy is to address both market failures. Moreover, Schneider and Goulder (1997) show that policies to address knowledge spillovers are more effective if they address all knowledge spillovers, rather than focusing on R\&D pertaining to alternative energy. Nonetheless, as targeted R\&D subsidies are likely to be more politically popular than either broad-based R\&D measures or restrictive emissions targets, it is useful to explore the potential of each mechanism both individually and in tandem.

To address this question, I use the ENTICE-BR model of climate policy (Popp forthcoming). ENTICE-BR extends the ENTICE model (Popp, 2004) to include policy-induced R\&D on both energy efficiency and a carbon-free backstop energy technology source. Both ENTICE models build on the well-known DICE model of climate change (Nordhaus, 1994; Nordhaus and Boyer, 2000). The DICE model is a dynamic growth model of the global economy that includes links between economic activity, carbon emissions, and the climate. Because it includes both costs and benefits of climate change, it allows the modeler to simulate optimal paths for control of carbon emissions. As such, unlike the analysis by Schneider and Goulder, I am able to calculate optimal policies for both carbon taxes and R\&D subsidies. Moreover, I examine how the optimal policy for each changes depending on whether the other market failure has also been addressed.

\section{The ENTICE Model}

To examine R\&D policies to address climate change, one must use a climate policy model that explicitly links climate policy and innovation. Typically, these models include such links in one of two ways. Bottom-up models include a detailed specification of energy systems, but typically do not include detailed modeling of the overall macroeconomy. Such models usually implement induced technological change with a learning-by-doing framework, in which the costs of various technologies decrease with experience. Examples include Manne and Richels (2004), Grübler and Messner (1998), and Messner (1997). Because these models do not 
address the opportunity costs of any new research efforts, they tend to provide overly optimistic results concerning the potential of technological change. ${ }^{3}$ Topdown models focus on the links between environmental policy and macroeconomic performance. Endogenous technological change in these models typically comes through accumulated investment in research and development (R\&D). Recent models of this nature include Goulder and Schneider (1999), Nordhaus (2002), and Buonanno et al. (2003). In addition, Gerlagh and van der Zwaan (2003) endogenize technological change in a top-down model using learning-by-doing. Of these models, only Goulder and Schneider and Gerlagh and van der Zwaan include a choice of multiple energy technologies, including a carbon-free alternative.

The ENTICE-BR model belongs to this second group of models. It is a topdown model providing explicit links between economic activity and environmental damages. The model uses the basic dynamic growth model framework of the DICE model (Nordhaus, 1994; Nordhaus and Boyer, 2000), but includes explicit links between climate policy and climate-friendly R\&D. ${ }^{4}$ Climate-friendly R\&D can come in one of two forms: as R\&D designed to improve overall energy efficiency, or $R \& D$ that helps reduce the cost of the carbon-free energy source. The model is calibrated to a base year of 1995, and is solved in 10-year increments for a period of 350 years. Figure 1 illustrates the logic of the ENTICE-BR model. Key equations

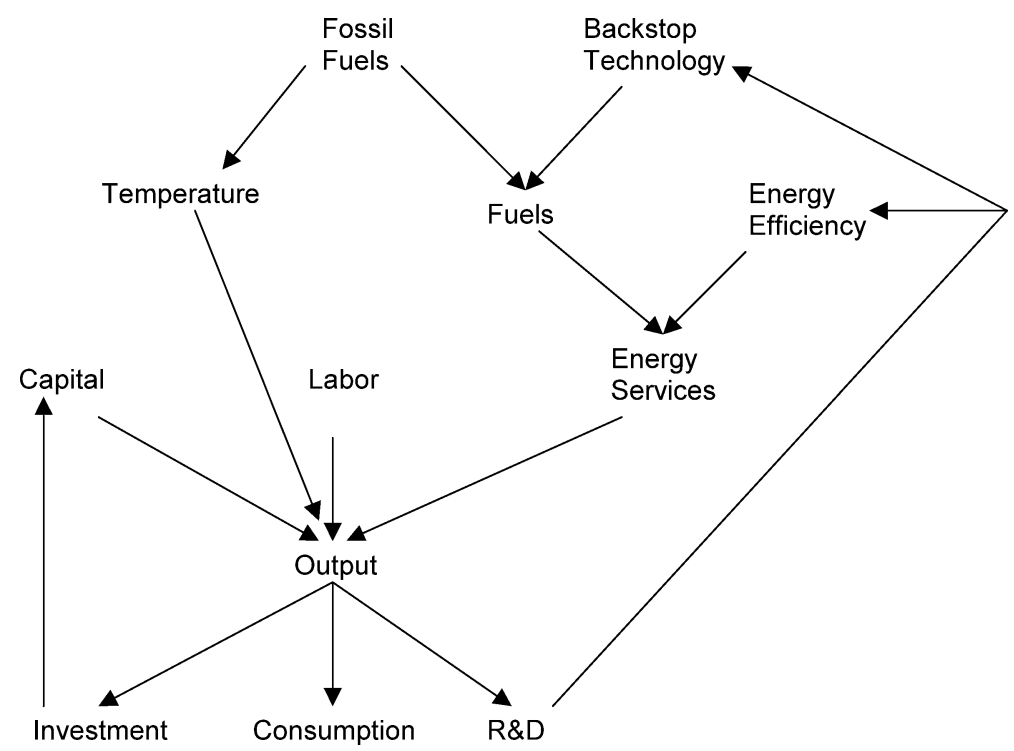

Figure 1. Schematic of the ENTICE-BR Model. Figure 1 illustrates the logic of the ENTICE-BR model. Capital, labor and energy services are combined to produce output, which can be used for consumption, or reinvested into energy R\&D or other investment. As described in the text, energy services combines two types of fuels (fossil fuels and a non-carbon backstop technology) and energy efficiency technologies. The use of fossil fuels leads to increased atmospheric temperature, which lowers output through a damage function. 
pertaining to the energy research sector are presented below. Interested readers are referred to Popp (forthcoming, 2004) for more detailed presentation of the model structure.

\subsection{STRUCTURE OF THE MODEL}

In both the DICE and ENTICE models, the goal of the model is to maximize the present value of per capita utility, which increases along with increased per capita consumption, subject to various economic and environmental constraints. One important difference between ENTICE and the original DICE model is that energy use must enter the production function explicitly, so that the potential benefits of energy saving research can be captured. As illustrated in Figure 1, total energy services, which are defined below, are used along with capital and labor to produce output. Defining output as $Q_{t}$, labor as $L_{t}$, the physical capital stock, $K_{t}$, and effective energy units, $E_{t}$, the production function used in ENTICE-BR is:

$$
Q_{t}=A_{t} K_{t}^{\gamma} L_{t}^{1-\gamma-\beta} E_{t}^{\beta}-p_{F, t} F_{t}-p_{B, t} B_{t}
$$

Energy services include both fossil fuels, $F_{t}$, and backstop energy, $B_{t}$. Note that the cost of both energy sources, $p_{F, t}$ and $p_{B, t}$, are subtracted from final output, and that both prices vary over time. Fossil fuels are measured in tons of carbon, so that the price of fossil fuels is thus the price of energy that generates one ton of carbon emissions. ${ }^{5}$ Backstop energy units are converted to represent the equivalence of one ton of carbon-based energy, or carbon-ton equivalence (CTE). Their price is defined below. The model is made dynamic by the various uses for output, which can satisfy current consumption needs, or be invested into the physical capital stock or as energy R\&D. ${ }^{6}$ Energy R\&D either increases the level of energy efficiency technology or lowers the cost of the backstop technology. The environmental component of the ENTICE-BR model links fossil fuel usage to increases in atmospheric temperature. An associated damage function results in lower levels of output as temperature increases.

As the main difference between the DICE model and ENTICE-BR is the energy research sector, I discuss those components of the model in greater detail. Effective energy units, $E_{t}$, uses a nested constant elasticity of substitution (CES) framework to aggregate the contributions of fossil fuels, the backstop energy source, and knowledge pertaining to energy efficiency. The first nest, introduced in Popp (2004), combines energy-efficiency knowledge and fuel consumption into the composite input of effective energy units. The second nest, between fossil fuels and the backstop technology, follows the work of van der Zwaan et al. (2002). This specification models the backstop and fossil fuels are imperfect substitutes, allowing for the possibility of "niche markets" for the backstop technology even when the price of the backstop exceeds fossil fuel prices. In each nest, the ease of substitution is represented by $\rho_{i}$. The case of perfect substitution is $\rho_{i}=1$. The elasticity of 
substitution is $1 /\left(1-\rho_{i}\right)$. Given this, effective energy units are modeled as:

$$
E_{t}=\left[\alpha_{H} H_{E, t}^{\rho_{H}}+\left(\left(\frac{F_{t}}{\alpha_{\Phi} \Phi_{t}}\right)^{\rho_{B}}+B_{t}^{\rho_{B}}\right)^{\rho_{H} / \rho_{B}}\right]^{1 / \rho_{H}}
$$

Equation (2) states that the total energy requirements for production must be met either by the use of fossil fuel or by technological advances that substitute for fossil fuels. Note that technology affects Equation (2) in one of two ways. $H_{E, t}$ represents technological advances that replace fuels in production, and can thus be thought of as improvements to energy efficiency. This stock of knowledge responds endogenously to changes in policy, through an invention possibilities frontier that is described below. $\alpha_{H}$ is a scaling factor that determines the level of energy savings resulting from new knowledge. ${ }^{7}$

In addition, technology influences the level of the backstop technology chosen by lowering the cost of this input. The backstop technology represents energy sources, such as wind or solar power, that are assumed abundant, and thus available at constant marginal cost. Currently, the high costs of these technologies limit their potential contribution to energy consumption. However, we expect that technological advances will lower their costs over time. Defining $H_{B, t}$ as the stock of knowledge pertaining to the backstop, and using $\eta$ to represent the relationship between new knowledge and prices, the backstop price at time $t$ is:

$$
p_{B, t}=\frac{P_{B, 0}}{H_{B, t}^{\eta}}
$$

The contribution of new energy R\&D to the knowledge stocks $H_{E, t}$ and $H_{B, t}$ is determined by an invention possibilities frontier, which translates $R \& D$ into new contributions to knowledge. Knowledge is cumulative, so that these contributions are added to the previous knowledge stock. Defining $R_{i, t}$ as R\&D on research for each technology at time $t$, the knowledge stocks are given as

$$
H_{i, t}=a R_{i, t}^{b_{i}} H_{i, t}^{\phi}+\left(1-\delta_{H}\right) \cdot H_{i, t-1}, \quad i=E, B
$$

Because the model is solved in 10-year increments, Equation (4) assumes that the main impact of a new technology occurs within 10 years. This is consistent with empirical work on the effect of energy R\&D (Popp, 2001), as well as broader studies on rates of diffusion (see, for example, the results cited in Karshenas and Stoneman, 1995). I assume that both $b_{i}$ and $\phi_{i}$ lie between 0 and 1. As discussed in Popp (2004), $\phi_{i}<1$ assumes there are diminishing returns to research across time. Since energy R\&D is specialized within a given field, it becomes more and more difficult to find new inventions as the knowledge frontier moves out. Popp (2002) provides supporting evidence. Similarly, $b<0$ assumes diminishing returns to research at any given time.

Finally, because of the public goods nature of knowledge, the role of market failures in R\&D must be considered. As noted earlier, virtually all empirical studies of $R \& D$ find that the social returns to $R \& D$ are greater than the private returns to 
R\&D. Since firms will invest until the private rates of return to $R \& D$ are equal to the rates of returns on other investments, underinvestment in R\&D will occur. I model these positive externalities by constraining the social rate of return for $R \& D$ to be four times that of investment in physical capital.

This constraint provides an additional avenue through which policymakers can influence R\&D. High social rates of return to R\&D occur because knowledge spillovers prevent firms from capturing the entire economic return on their innovations. Governments can close the gap between the social rate of return on $R \& D$ and other investments by subsidizing $\mathrm{R} \& \mathrm{D}{ }^{8}$ In principle, governments desiring to enhance efficiency would subsidize $R \& D$ until $R \& D$ levels increase enough so that the marginal gains from an additional dollar of $R \& D$ are no greater than the marginal gains from a dollar invested elsewhere in the economy. Removing the rate of return constraint assumes that government policies, such as R\&D subsidies, are in place to correct market failures in the research sector.

In addition, since empirical work suggests that at least some energy $R \& D$ will come at the expense of other forms of $R \& D,{ }^{9}$ we need to account for the opportunity cost of $R \& D$. Since the social rate of return on $R \& D$ is four times higher that of other investment, losing a dollar of other R\&D has the same effect as losing four dollars of other investments. This is modeled by subtracting four dollars of private investment from the physical capital stock for each dollar of R\&D crowded out by energy $R \& D$, so that the net capital stock is:

$$
K_{t}=\left\{I_{t}-4 * \text { crowdout } *\left(R_{E, t}+R_{B, t}\right)\right\}+(1-\delta) K_{t-1},
$$

where crowdout represents the percentage of other R\&D crowded out by energy $\mathrm{R} \& \mathrm{D}, I_{t}$ represents investment in physical capital, and $\delta$ is the depreciation rate of capital over time. ${ }^{10}$

\subsection{CALIBRATION}

Before presenting the results of simulations, it is first necessary to discuss the values used for key parameters in the equations above. As mentioned earlier, the model is calibrated using 1995 as the base year. Parameters are chosen so that output and emissions closely match the results of the basic DICE model (Nordhaus, 1994; Nordhaus and Boyer, 2000), as discussed in Popp (2004). Of particular importance to the following analysis are the values of parameters used to model energy consumption and R\&D. I highlight these key values below. Readers interested in more details on calibration are referred to the appendix. ${ }^{11}$ Key parameters include:

- $\rho_{H}$ and $\rho_{B}$, the substitution parameters in Equation (2),

- $\eta$, describing the relationship between knowledge and backstop prices in Equation (3), 
- $a, b$, and $\phi$ : parameters in the invention possibilities frontier (4), and

- $\alpha_{H}$, the scaling factor for the effect of energy-efficiency human capital.

As shown in Popp (forthcoming, 2004), the results of the ENTICE model are most sensitive to changes in $\rho_{H}$ and $\rho_{B}$. Increases in these parameters lead to increases in the amount of $R \& D$ induced by changes in the price of fossil fuels (such as a carbon tax). Climate policies are less costly when more R\&D is induced. Based on Popp (2002), I choose $\rho_{H}$ so that the model produces an elasticity of energy-efficiency $R \& D$ with respect to energy prices of 0.35 for the base model. ${ }^{12}$

Unlike $\rho_{H}$, the value of $\rho_{B}$, is not freely chosen. Because it describes the substitutability between fossil fuels and the backstop technology, its value is determined by the starting price of the backstop technology. Unfortunately, a wide range of possibilities for the starting price exists. Popp (forthcoming) presents sensitivity analysis for three initial price levels, $\$ 400, \$ 1200$, and $\$ 2000$ per carbon ton equivalent (CTE) of backstop energy. ${ }^{13}$ Because the model is most sensitive to lowering the backstop price, in this paper I focus on the mid-range value of $\$ 1200$ per carbon ton equivalent of backstop energy, as well as the low initial backstop price of $\$ 400 / \mathrm{CTE}$ of backstop energy. As noted in Popp (forthcoming), the resulting elasticity of substitution $\left(\rho_{B}\right)$ using this low starting price yields very high elasticities of $\mathrm{R} \& \mathrm{D}$, and should be considered an optimistic alternative.

Next, I choose a value for $\eta$, which relates increases in backstop R\&D to backstop price decreases. Unfortunately, no good empirical estimates of this parameter exist. Popp (forthcoming) presents results for two values, 0.5 and 1.0. These yield progress ratios of 24 and $50 \%$ respectively. A 50\% progress means that a doubling of the knowledge stock reduces the backstop price by $50 \%$. I use the $24 \%$ progress ratio as the base case, as Popp (forthcoming) shows that the marginal returns to R\&D are more realistic when using this value.

I choose parameters for the inventions possibility frontier to satisfy the following conditions. First, I choose a value for $a$ so that the change in energy R\&D between 1995 and 2005 in the optimal policy simulation is consistent with the elasticity of 0.35 . Values of $b$ and $\phi$ are then chosen so that future elasticities fit the desired time path - falling slowly in the near future due to diminishing returns to $R \& D$, as suggested in Popp (2002). Finally, I calibrate the scaling factor $\alpha_{H}$ so that a dollar of new energy R\&D results in four dollars of energy savings, as suggested in Popp (2001).

\section{Simulations}

Because the ENTICE-BR model includes environmental damages, it can be used to calculate an optimal climate policy in which marginal benefits equal marginal costs. Such a policy meets a benefit-cost criterion of maximizing total net benefits, and is equivalent to using carbon taxes to correct the environmental externality described 
in Section $1 .{ }^{14}$ In addition, removing the constraint that the rate of return of energy $\mathrm{R} \& \mathrm{D}$ be four times that of other investment is equivalent to using policy to correct market failures for $R \& D$, such as government funded $R \& D$ that supplements private R\&D effort. ${ }^{15}$ In this section, I use the model described above to compare the effects of alleviating one or both of these market failures. I begin by summarizing the main results of using an optimal carbon tax, which corrects the environmental externality, but does not address knowledge spillovers. I then consider how the results change when R\&D subsidies are used to correct the market failures resulting from knowledge spillovers. Next, I examine sensitivity of the results to key assumptions in the model. Finally, because the level of emissions reductions resulting from an optimal tax is lower than often proposed by policymakers, I also consider whether R\&D subsidies affect the desirability of more restrictive emissions reduction proposals.

\subsection{OPTIMAL ENVIRONMENTAL POLICY}

Popp (forthcoming) presents the results of a simulated optimal carbon tax without $\mathrm{R} \& \mathrm{D}$ subsidies. As is typical of economic models that solve for an optimal climate policy, the results recommend that climate policy proceed slowly. Because carbon emissions stay in the atmosphere for a long period of time, the marginal damage from any additional ton of emissions is low. Thus, gradually phasing in carbon reduction lowers the opportunity cost of reducing emissions without having much impact on the global climate. Figure 2 shows the carbon tax for the first 100 years. The tax starts at a value of $\$ 10.30$ per ton carbon $(\mathrm{tC})$ in $2005,{ }^{16}$ and rises to $\$ 72.59 / \mathrm{tC}$ by 2105 . To compare the magnitude of the tax to other policy goals, Nordhaus and Boyer (2000) calculate a tax of $\$ 52.48 / \mathrm{tC}$ to restrict emissions to 1990 levels, and a carbon tax of $\$ 267.69 / \mathrm{tC}$ in 2105 to limit concentrations to twice those of preindustrial levels. Similarly, using the DEMETER model, Gerlagh and van der Zwaan calculate a tax of $\$ 10 / \mathrm{tC}$ in 2000 and taxes ranging from $\$ 400 / \mathrm{tC}$ to $\$ 600 / \mathrm{tC}$ in 2100 to limit temperature increases to two degrees Celsius.

The emissions reductions resulting from this carbon tax can be found by comparing the lines for business as usual (BAU) and optimal tax in Figure 3. Compared to BAU, carbon emissions under an optimal carbon tax fall by just $3.2 \%$ in 2005 , by $5.4 \%$ in 2025 , and by $15.4 \%$ in $2105 .{ }^{17}$ As a result of this, atmospheric temperature continues to rise, although at a slightly slower pace, as shown in Figure 4. Here, and in the figures that follow, solid lines illustrate results under BAU, and dashed lines results using an optimal carbon tax only. Lines marked with additional symbols show results from a simulation also including $R \& D$ subsidies. These are discussed in Section 3.2.

Table I and Figure 5 show R\&D spending on energy efficiency and the backstop technology (as well as under the R\&D subsidy policy to be discussed below). In the base year (1995), there are $\$ 10$ billion of energy $R \& D$, and $\$ 1$ billion of backstop energy R\&D. ${ }^{18}$ Based on results from Popp (2002), the model is calibrated so that 


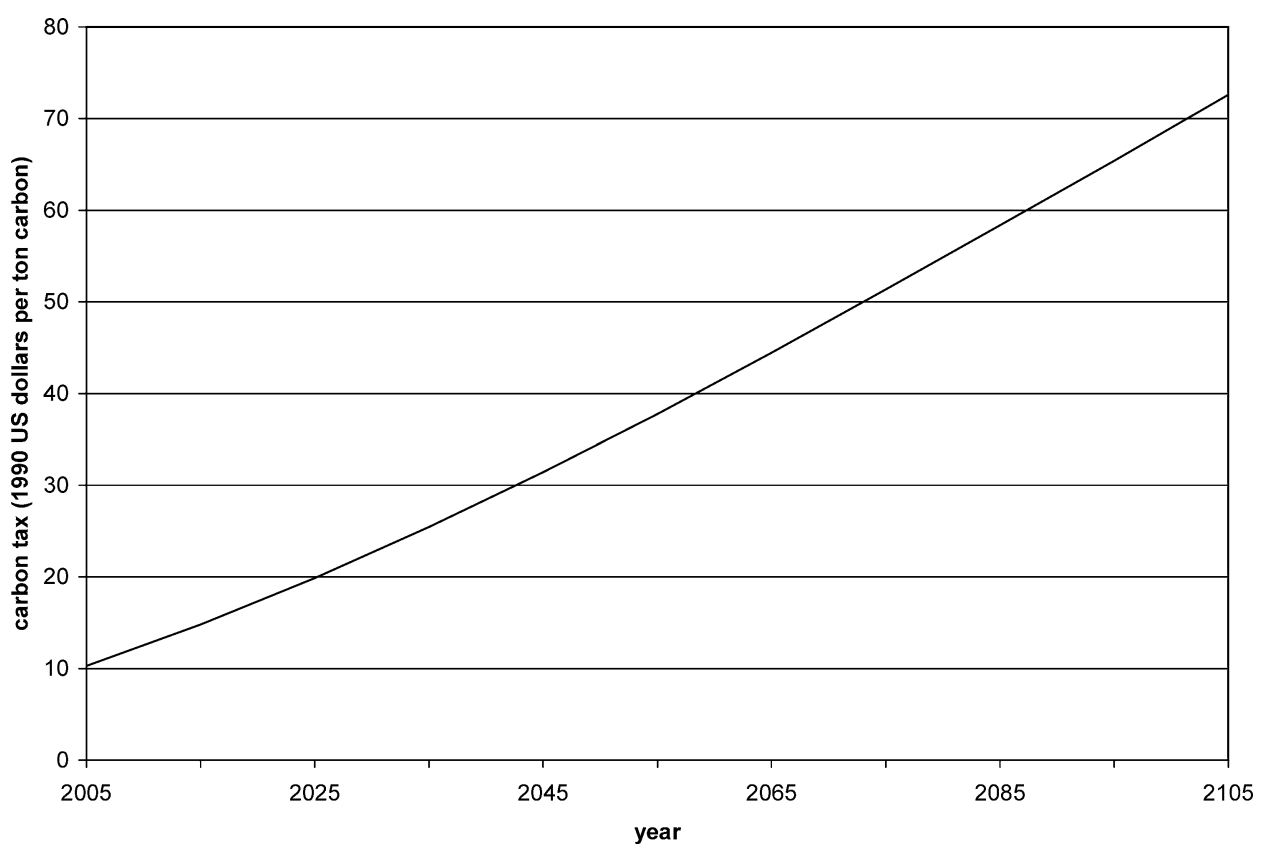

Figure 2. Optimal Carbon Tax rates.

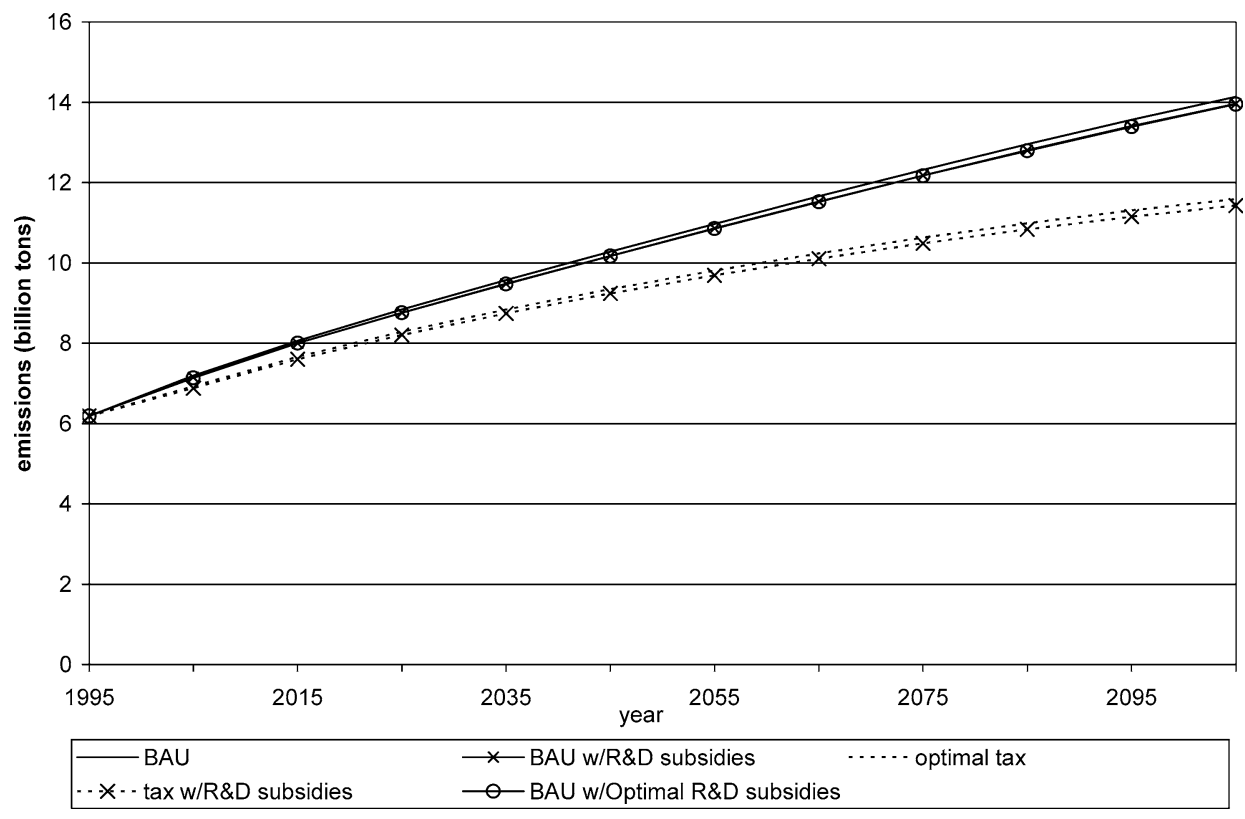

Figure 3. Carbon Emissions Under Optimal Climate Policies. The figure shows annual carbon emissions under both business and usual (BAU) and an optimal carbon tax policy. Note that R\&D subsidies, by themselves, result in very small reductions in emissions. This is true in both the BAU and optimal tax simulations. Policies aimed directly at emissions are needed to achieve reductions. 


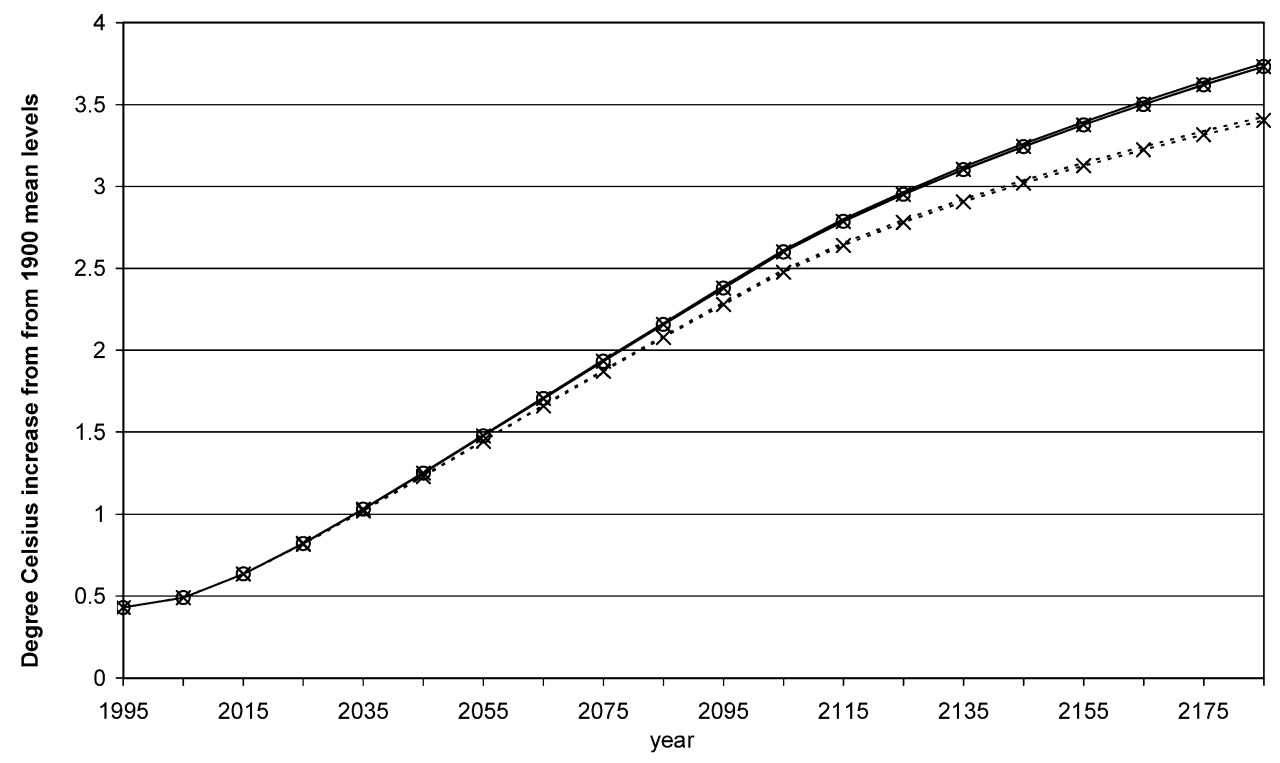

\begin{tabular}{|c|c|}
\hline$-\mathrm{BAU}$ & $\rightarrow \leftarrow$ BAU w/R\&D subsidies $\quad \cdots \cdots$ optimal tax \\
\hline$\cdots \ngtr \cdots$ tax \& subsidy & ○-BAU w/Optimal R\&D subsidies \\
\hline
\end{tabular}

Figure 4. Atmospheric Temperature Under Optimal Climate Policies. The figure shows how the departure of global mean temperature from 1990 levels, reported in degrees Celsius is affected by carbon taxes and/or R\&D subsidies. As with emissions, R\&D subsidies by themselves have little effect on temperature.

the initial elasticity of energy $R \& D$ with respect to energy prices is 0.35 , and so that the elasticity falls over time due to diminishing returns to research, as discussed in Section 2. This results in $\$ 13$ billion of energy efficiency R\&D in 2005, and $\$ 1.37$ billion of backstop energy R\&D in 2005 under the optimal policy.

Finally, it is useful to consider the overall economic impact of the carbon tax. I calculate the net economic impact as the present value of consumption with policy minus the present value of consumption under BAU for the 350 years of the ENTICE simulation. Simply correcting the environmental externality through an optimal carbon tax increases welfare by $\$ 2.31$ trillion over the time frame of the simulation.

\subsection{R\&D SUBSIDIES}

The above results correct show the effects of policy designed to correct the environmental externality market failure. However, as discussed in Section 2, the potential of $R \& D$ to reduce the costs of complying with climate change is limited by additional market failures for $R \& D$. Because firms cannot fully capture the social benefits of their research, they will underinvest in energy (and other) R\&D. The 
R \& D SUBSIDIES AND CLIMATE POLICY

TABLE I

Energy R\&D Spending Over Time

\begin{tabular}{|c|c|c|c|c|}
\hline & 2005 & 2025 & 2055 & 2105 \\
\hline \multicolumn{5}{|l|}{ Energy Efficiency $R \& D$} \\
\hline BAU & 13.08 & 19.67 & 26.37 & 37.96 \\
\hline Subsidy & 0 & 2.02 & 5.85 & 11.57 \\
\hline Total w/R\&D subsidies & 13.08 & 21.69 & 32.22 & 49.53 \\
\hline optimal tax & 13.28 & 19.91 & 26.88 & 38.89 \\
\hline Subsidy & 0.13 & 2.46 & 6.56 & 12.11 \\
\hline Total w/R\&D subsidies & 13.41 & 22.37 & 33.44 & 51.00 \\
\hline \multicolumn{5}{|l|}{ Backstop R\&D } \\
\hline BAU & 1.28 & 1.70 & 2.27 & 3.43 \\
\hline Subsidy & 0.06 & 0.23 & 0.66 & 1.73 \\
\hline Total w/R\&D subsidies & 1.34 & 1.93 & 2.93 & 5.16 \\
\hline optimal tax & 1.37 & 1.83 & 2.44 & 3.61 \\
\hline Subsidy & 0.07 & 0.29 & 0.81 & 2.06 \\
\hline Total w/R\&D subsidies & 1.44 & 2.12 & 3.25 & 5.67 \\
\hline \multicolumn{5}{|l|}{ Percent Change from BAU } \\
\hline \multicolumn{5}{|l|}{ Energy Efficiency $R \& D$} \\
\hline BAU & N/A & N/A & N/A & $\mathrm{N} / \mathrm{A}$ \\
\hline W/R\&D subsidies & $0.0 \%$ & $10.3 \%$ & $22.2 \%$ & $30.5 \%$ \\
\hline optimal tax & $1.5 \%$ & $1.2 \%$ & $1.9 \%$ & $2.4 \%$ \\
\hline W/R\&D subsidies & $2.5 \%$ & $13.7 \%$ & $26.8 \%$ & $34.4 \%$ \\
\hline \multicolumn{5}{|l|}{ Backstop $R \& D$} \\
\hline $\mathrm{BAU}$ & N/A & N/A & N/A & $\mathrm{N} / \mathrm{A}$ \\
\hline w/R\&D subsidies & $4.7 \%$ & $13.5 \%$ & $29.1 \%$ & $50.4 \%$ \\
\hline optimal tax & $7.0 \%$ & $7.6 \%$ & $7.5 \%$ & $5.2 \%$ \\
\hline w/R\&D subsidies & $12.5 \%$ & $24.7 \%$ & $43.2 \%$ & $65.3 \%$ \\
\hline
\end{tabular}

Table I presents levels of energy R\&D spending over time, in billions of 1990 US dollars. BAU shows R\&D spending under business as usual without any R\&D subsidies. Subsidy shows the amount of R\&D subsidy that addresses knowledge spillovers, but not the environmental externality, and BAU with $R \& D$ subsidies presents the combined total of BAU R\&D and the subsidy. Similarly, optimal tax shows R\&D levels under a carbon tax designed to correct the environmental externality, but without R\&D policy to address knowledge spillovers. Here, subsidy shows the level of R\&D subsidies needed to address both the environmental and knowledge market failures, and optimal tax with R\&D subsidies shows the total R\&D (including subsidies) when the policy is in place. Finally, the bottom half of the table shows the increase from BAU R\&D for each policy scenario.

main contribution of this paper is to ask how, if at all, the potential of $R \& D$ changes when such market failures are corrected. This section evaluates the potential of government R\&D subsidies as part of a climate policy scenario.

Because two market failures, the environmental externality and knowledge spillovers, need to be corrected, there are three possible policies to consider. They differ by addressing either one or both of these two market failures. First, one could imagine a policy that simply corrects the knowledge spillover problem, but ignores 


\section{a. Backstop Energy R\&D}

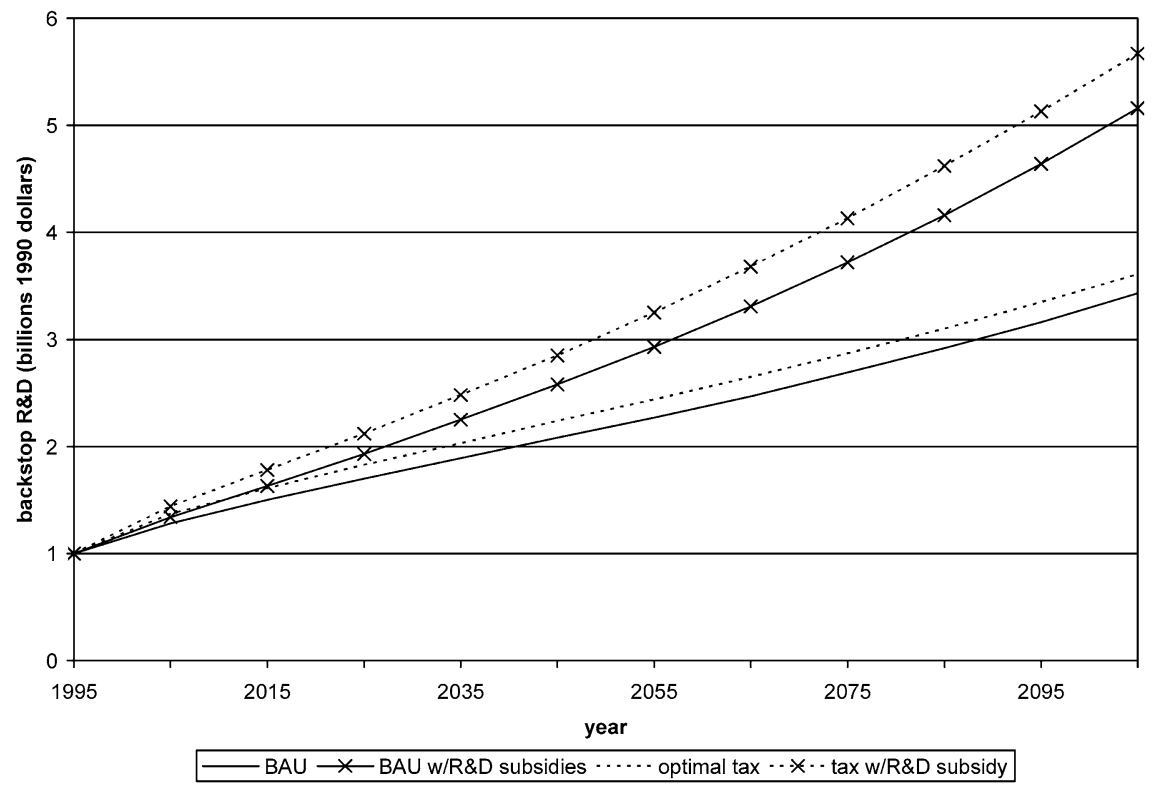

\section{b. Energy Efficiency $R \& D$}

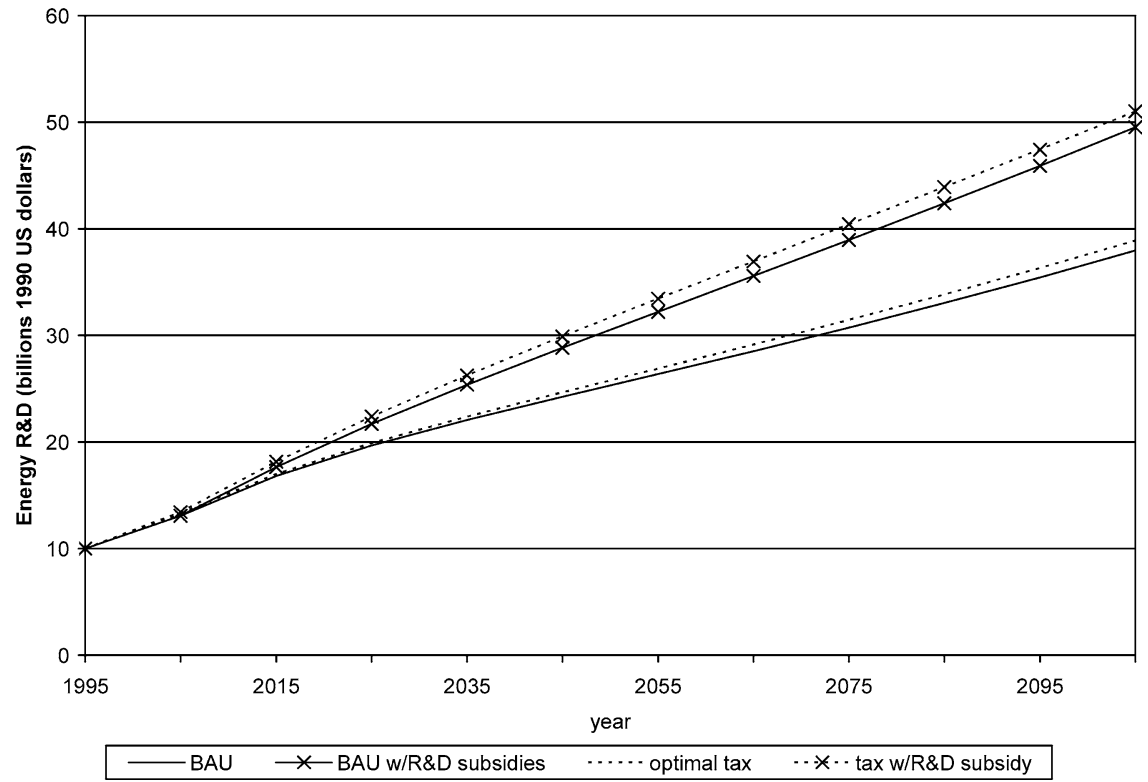

Figure 5. Energy R\&D Under Optimal Climate Policies. Panel a shows the level of backstop energy $R \& D$, and panel $b$ the level of energy efficiency R\&D, both in billions of 1990 US dollars. As can be seen by comparing the BAU and optimal tax lines with and without subsidies, policies that correct $R \& D$ market failures induce more additional R\&D than does the carbon tax itself. 
the environmental externality. This would be equivalent to removing the rate of return constraint in ENTICE-BR, but not implementing a carbon tax. While such a policy corrects for knowledge spillovers, it ignores the environmental benefits that emerge from energy R\&D. Second, the government could use R\&D subsidies that consider both the social benefits of knowledge spillovers and the environmental benefits provided by the R\&D. Such subsidies will, of course, be greater than the subsidies under the first policy option. In this case, the total level of $R \& D$ would be equivalent to the $R \& D$ under a carbon tax with the rate of return constraint removed. ${ }^{19}$ Finally, rather than using R\&D subsidies in isolation, the government can use subsidies in tandem with an optimal carbon tax. Such a policy would be preferred to either using a carbon tax or subsidies alone, as it addresses both market failures. ${ }^{20}$

Table I and Figure 5 show R\&D spending on energy efficiency and the backstop technology under the various policy scenarios, as well as the percentage by which $R \& D$ increases from BAU under each policy scenario. In the table, BAU with R\&D subsidies represents the first policy discussed above, in which only knowledge spillovers are considered. Optimal tax with R\&D subsidies gives the level of $\mathrm{R} \& \mathrm{D}$ under both the second and third policies discussed above, in which subsidies address both the environmental externality and knowledge spillovers. In the base year (1995), there are $\$ 10$ billion of energy $R \& D$, and $\$ 1$ billion of backstop energy $R \& D .^{21}$ In the short run, simply implementing an optimal tax increases $R \& D$ more than correcting R\&D market failures. For example, compared to BAU, backstop R\&D increases by 7 percent under the carbon tax (which corrects the environmental externality, but not the spillover problem), but just 4.7 percent in the BAU scenario with R\&D subsidies (which corrects the spillover problem, but not the environmental externality).

However, while the percentage of $R \& D$ induced by the carbon tax remains relatively constant over time, the percentage subsidy required to equate private and social returns to R\&D grows. Each additional R\&D dollar not only benefits current consumers, but also provides additional building blocks for future research. Thus, as shown in the figures, the major difference in long run $R \& D$ comes from correcting the spillover problem, rather than the environmental externality. By the middle of the century, the optimal R\&D subsidy is 43 percent higher than BAU R\&D. Furthermore, after correcting for knowledge spillovers, the additional increment to $\mathrm{R} \& \mathrm{D}$ from also acknowledging the environmental externality is small, as shown by the differences between the lines labeled BAU with R\&D subsidies and optimal tax with $R \& D$ subsidies in Figure 5. There is a larger difference between $R \& D$ with and without subsidies under BAU (or under an optimal tax policy) than there is between R\&D with and without a tax when a subsidy is in place. Thus, while climate policy will induce some increases in climate-friendly $R \& D$, the most significant gains to $\mathrm{R} \& \mathrm{D}$ spending come from directly addressing the market failures resulting from knowledge spillovers.

Nonetheless, note from Figures 3 and 4 that while subsidies do increase energy $R \& D$ in the long-run, they have little impact on other important variables. Recall 
that, in these figures, the two solid lines show emissions under BAU and the dashed lines show emissions with the optimal carbon tax. Symbols mark the lines representing policies with R\&D subsidies. These figures emphasize the importance of environmental policy for reducing emissions. While there is a significant drop in emissions between any BAU scenario versus any carbon tax scenario, there is almost no change in emissions under BAU versus BAU with R\&D subsidies only. Similarly, the addition of R\&D subsidies does not lead to further emissions reductions after a carbon tax is in place. Of course, similar trends hold for temperature.

Moreover, using R\&D subsidies leads to virtually no change the optimal level of the carbon tax, which remains within one-half of one percent of its original level after subsidies are included. The carbon tax rate is based on the marginal damage of emissions. The marginal damage curve for carbon emissions in any given year is relatively flat, as one additional ton of carbon is just a small addition to total concentrations. While R\&D allows emissions reductions to be achieved at lower cost, it does not change the marginal benefits gained from reducing emissions, which is the avoided marginal damage. A tax set at this level is still necessary to force consumers and producers to consider the environmental costs of their actions when consuming fossil fuels. While R\&D subsidies can augment other environmental policy, and can help lower the costs of complying with these policies, they cannot serve as a substitute for policies designed to restrict emissions! $!^{22}$

As would be expected, with such small impacts on emissions, the effects of R\&D subsidies on overall economic welfare are also small. Table II shows the welfare gains from four separate policies: R\&D subsidies only, optimal R\&D subsidies

TABLE II

Welfare Gains

\begin{tabular}{lcc}
\hline & Gain from BAU & \% of maximum welfare gain \\
\hline Optimal tax \& R\&D subsidies & 2.43 & $100 \%$ \\
Optimal tax only & 2.31 & $95 \%$ \\
Optimal R\&D subsidies only & 0.27 & $11 \%$ \\
R\&D subsidies only & 0.23 & $9 \%$ \\
\hline Restrict emissions \& R\&D subsidies & -3.61 & $-148 \%$ \\
Restrict emissions to 1995 levels & -3.75 & $-154 \%$ \\
\hline Backstop mandate \& R\&D subsidies & 1.68 & $69 \%$ \\
Backstop mandate & 1.57 & $64 \%$ \\
\hline
\end{tabular}

Table II summarizes the welfare gains under various optimal emissions policies, as well as under two alternative policies discussed in Section 3.4. Net economic welfare is measured as the difference in the present value of consumption between a policy and BAU simulation, and is presented in trillions of 1990 US dollars. The maximum welfare gain comes from a combination of optimal carbon taxes and R\&D subsidies, as this addresses both market failures. Note that R\&D subsidies themselves do not enhance welfare as much as policies that directly deal with the environmental externality from carbon emissions. 
only, an optimal tax only, or both an optimal tax and optimal R\&D subsidies. Of course, the maximum welfare gain is achieved when policy addresses both market failures. In this case, welfare improves by $\$ 2.43$ trillion during the period of the simulation. As shown in the table, most of this increase comes from the carbon tax. A carbon tax alone achieves $95 \%$ of these welfare gains. However, R\&D subsidies alone achieve just $10 \%$ of the maximum welfare gain.

The above results suggest that $R \& D$ subsidies can be a useful complement to other environmental policies, but do not have the ability to address the climate change problem alone. Thus, while policymakers may find it politically expedient to fall back on proposals for increased research efforts to confront climate change, significant progress cannot be made without complementary policies in place to restrict emissions. There are two reasons for the limited potential of R\&D subsidies. Most importantly, R\&D subsidies address market failures in the invention of new technologies, but do not provide incentives to adopt new technologies. Consider, for example, Figure 6, which shows the percentage of energy coming from backstop sources. Compared to BAU, this percentage increases by about five percentage points under a carbon tax. However, there is almost no change in the percentage when comparing BAU with and without $\mathrm{R} \& \mathrm{D}$ subsidies.

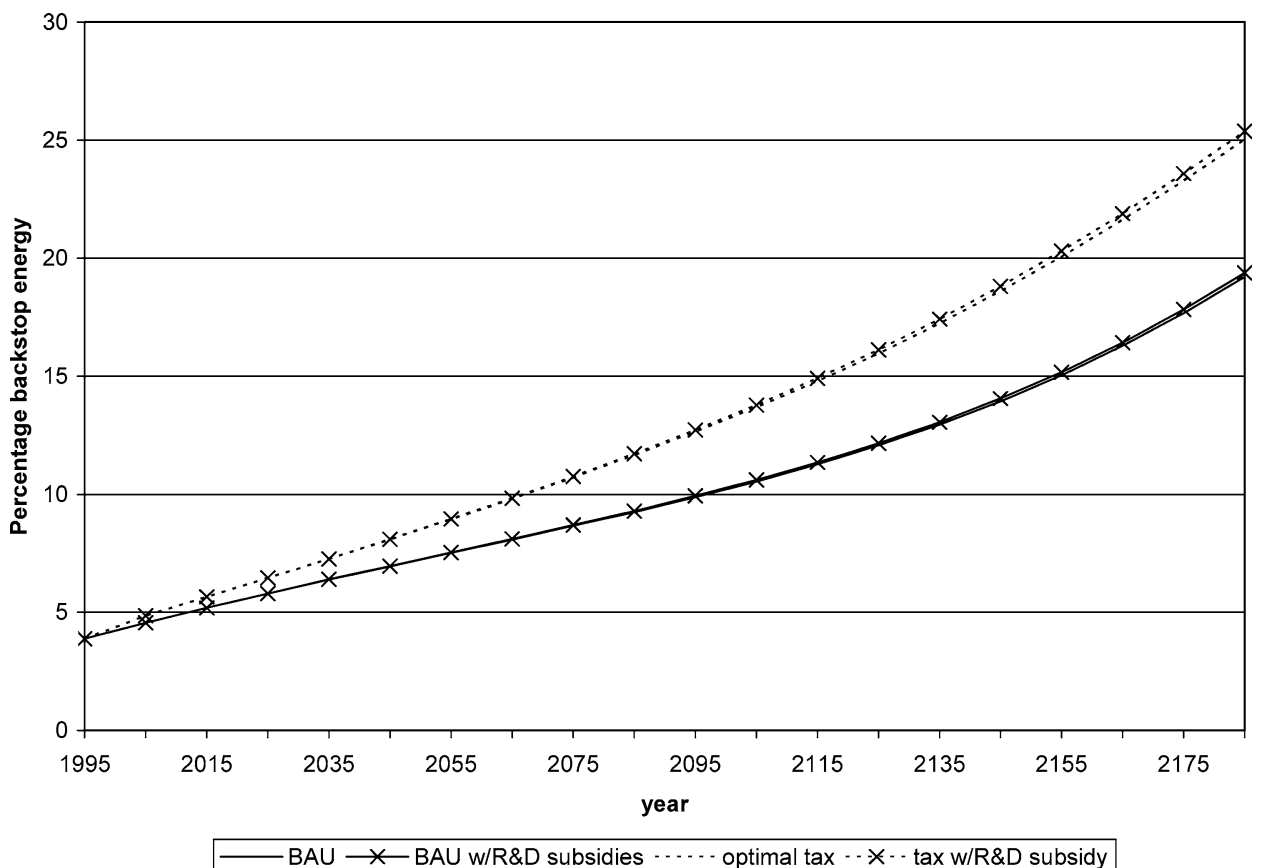

Figure 6. Percentage of Energy From Backstop Sources. The figure shows the percentage of energy from backstop sources under BAU or an optimal carbon tax. As with emissions, a policy addressing carbon emissions directly, such as a carbon tax, is necessary to increase this percentage. There is almost no change between BAU and BAU with R\&D subsidies. 
A second limitation of $R \& D$ subsidies comes from the opportunity costs of $R \& D . R \& D$ is performed by highly trained scientists and engineers. Shifting more resources towards one type of research results in fewer resources available for other research opportunities. For example, Goolsbee (1998) finds that one of the chief beneficiaries of $\mathrm{R} \& \mathrm{D}$ tax subsidies are scientists and engineers, as increased demand for their services leads to higher wages. Similarly, in Popp (2004), I present evidence that approximately one-half of the energy R\&D spending that took place in the 1970s and 1980s came at the expense of other R\&D. This lost R\&D comes at a high cost. Because of market failures for knowledge, the social returns to R\&D are high for all types of R\&D, not just for energy R\&D. Recall from Section 2 that the consensus from studies on the returns to $R \& D$ is that the social rates of return are approximately four times higher than the rates of return to other investments. Thus, taking one dollar from other R\&D projects has the same effect as taking four dollars from other types of investments. Indeed, the socially optimal level of R\&D subsidies found by the ENTICE-BR model account for this, as the rates of return to $R \& D$ remain twice that of other investment even after the constraint requiring the returns to be four times higher is removed. ${ }^{23}$ If the government ignores these social costs, and subsidizes energy R\&D until its rate of return is equal to that of other investments, net economic welfare actually falls due to the lost value of other $R \& D$. This result suggests that large-scale increases in energy R\&D budgets, such as suggested by the 1999 PCAST report, will have significant macroeconomic costs unless accompanied by other initiatives designed to reduce the effects of crowding out. Examples of such initiatives could include expanded resources for training of scientists and engineers, so that new researchers come from an expanded pool of scientists, rather than from other disciplines. Of course, efforts to increase the pool of available scientists take time, suggesting that rapid increases in R\&D budgets should be avoided.

\subsection{SENSITIVITY ANALYSIS}

The small role that R\&D subsidies play in the ENTICE-BR model may come as a surprise to many climate researchers. To better understand the limits to $R \& D$ subsidies as climate policy, in this Section I examine the sensitivity of the model to various key assumptions of the model. These are: (1) a lower initial backstop price of $\$ 400$, (2) increasing the progress ratio for backstop price decreases to 50 percent, (3) doubling the value of $b$ in the invention possibilities frontier (equation (4)) for each type of energy $R \& D$, (4) raising the value of $\phi$ in the invention possibilities frontier, (5) raising to eight the deviation between social and private rates of return on $R \& D$, (6) raising to eight the deviation between social and private rates of return for energy $R \& D$ only, (7) assuming no crowding out of other $\mathrm{R} \& \mathrm{D}$, and (8) assuming both a lower backstop price and no crowding out of R\&D. ${ }^{24}$ I focus on how changing these parameters affects the prospects for R\&D subsidies. Thus, I 
first show how changes in these parameters affect the magnitude of $R \& D$ subsidies, followed by the effects of changes on overall economic welfare. Readers interested in a more general discussion of the effects of changing parameters on other outputs of the model are referred to Popp (forthcoming).

Figure 7 shows the percentage of each type energy $R \& D$ that is subsidized (e.g. funded by the government) under each scenario. For backstop R\&D, note that assumptions about the initial backstop price (and consequently the elasticity of substitution between energy sources) have by far the biggest impact on subsidies. A lower backstop price means that alternative energy sources are closer to becoming competitive with fossil fuels. Whereas increased $R \& D$ cannot do enough to make the backstop competitive with a starting price of $\$ 1200$, increased R\&D can increase the speed at which the backstop becomes competitive at the lower starting price of $\$ 400 .{ }^{25}$ Moreover, the elasticity of substitution implied by this price suggests that the backstop and fossil fuels are better substitutes. Both of these features make nearterm backstop R\&D much more attractive with the lower starting price. Except for doubling $b$, all other changes mentioned above also increase backstop subsidies, but by smaller amounts. The next largest changes come from raising $\phi$ and by assuming no crowding out of R\&D.

In contrast, removing assumptions about crowding out have the biggest impact on energy efficiency subsidies. The next biggest impact is for raising the deviation between social and private rates of return, but the effect of this change is about 10 percent of the effect of removing crowding out. Interestingly, making the backstop more attractive by lowering its price makes subsidies for energy efficiency less attractive, as more resources are devoted to promoting the backstop technology instead.

Figure 8 shows the net welfare gains for an optimal tax policy, both with and without R\&D subsidies, for each of these assumptions, as well as the welfare gains from subsidies without climate policy. Here we see four sets of assumptions where the welfare effects of an optimal policy change significantly: a low backstop price, high social returns to energy R\&D only, no crowding out, and the low price/no crowding out combination. For the others, note that while changing these parameters changes the effects of energy $R \& D$, energy $R \& D$ is a small part of the total economy. Moreover, changing the parameters of the invention possibilities frontier affects both the baseline and policy case, so that energy R\&D also becomes more desirable even without policy. Finally, except for the case where a low initial price makes the backstop more attractive, the optimal emissions profile does not change much, so that any gains that do occur result in more output, rather than changes in climate. ${ }^{26}$ The figure also verifies the importance of crowding out as a limitation to R\&D subsidies. Removing the assumption of partial crowding out of R\&D makes R\&D subsidies more attractive. In fact, $R \& D$ subsidies alone increase welfare by more than the optimal tax alone in the case with no crowding out.

Finally, it is worth considering what many observers would argue is the "special nature" of energy R\&D. Many researchers in the climate change field advocate 
a. Backstop Energy $R \& D$

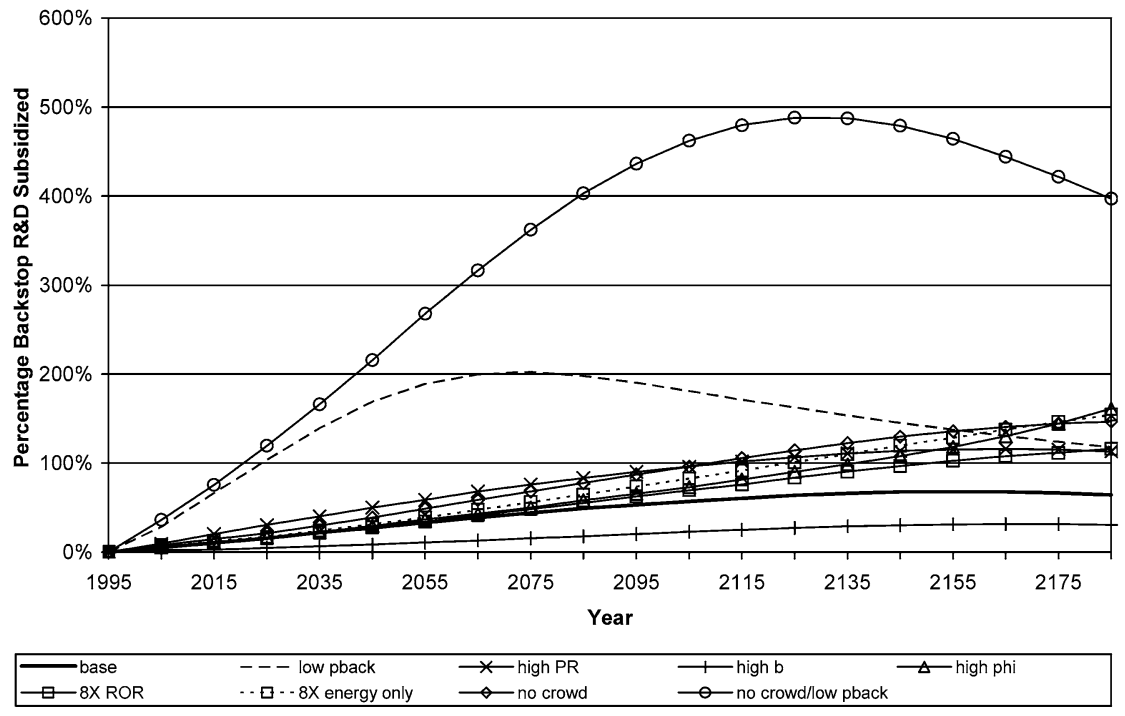

\section{b. Energy Efficiency $R \& D$}

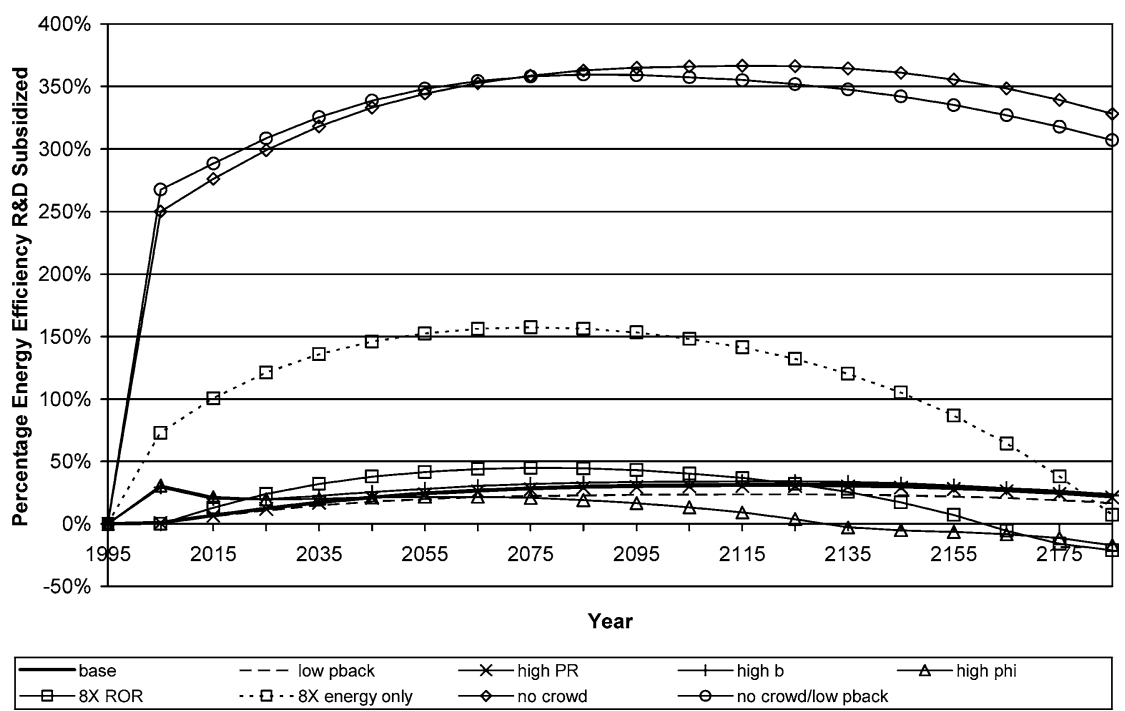

Figure 7. Percentage of R\&D Subsidized With Optimal Subsidy Rates. Panel a shows the percentage of backstop energy R\&D supported by subsidies, and panel b shows the same percentage for energy efficiency R\&D. For backstop R\&D, assumptions about the initial backstop price lead to the largest increase in subsidies. In contrast, energy efficiency $R \& D$ falls as the backstop price is lowered, as resources are shifted from energy efficiency $R \& D$ to backstop $R \& D$. In both cases, assumptions about crowding out and the returns to energy $R \& D$ are important. 


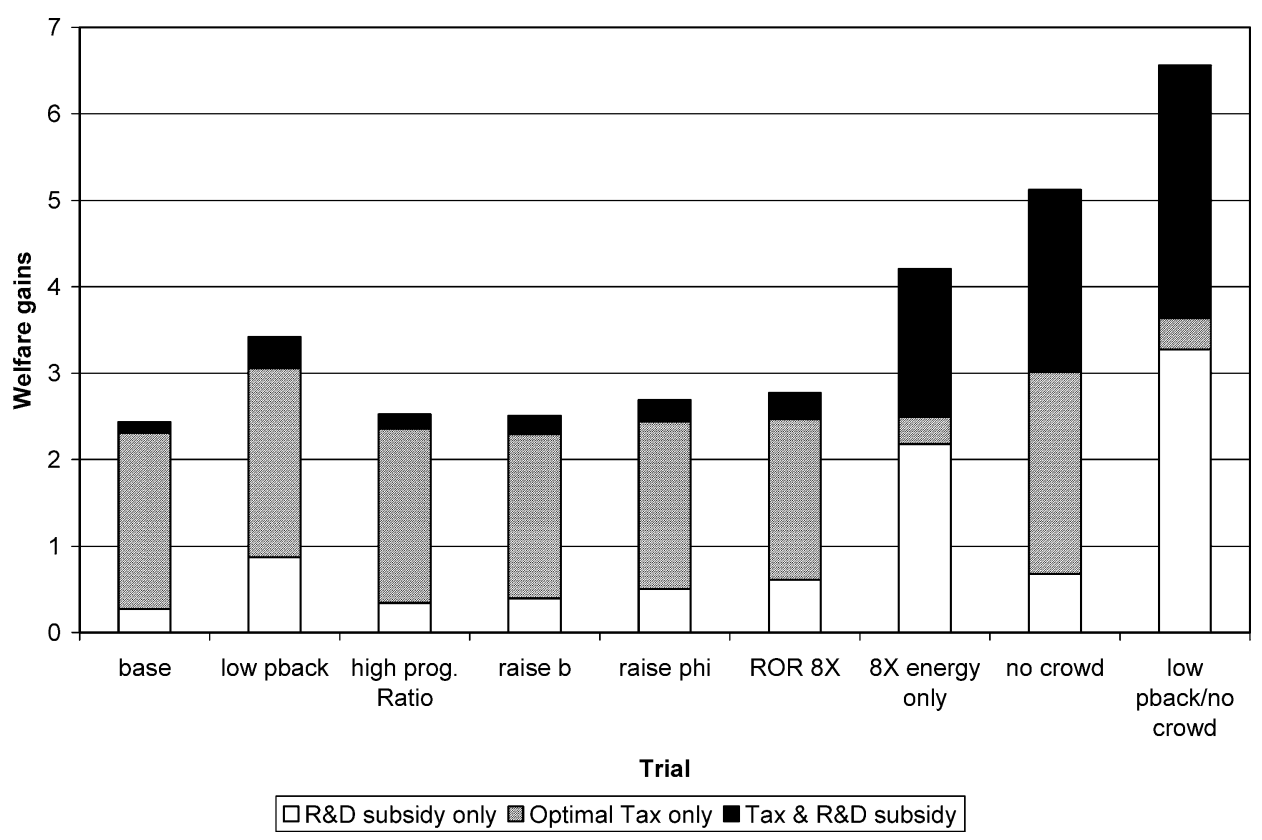

Figure 8. Sensitivity Analysis of Welfare Gains. The figure examines the sensitivity of welfare gains under various assumptions, with the gains expressed in trillions of 1990 U.S. dollars. Except for simulations with no crowding out or high returns to energy R\&D, subsidies remain ineffective when not paired with policies specifically designed to reduce emissions.

a major role for R\&D subsidies, arguing that the long-term payoffs, uncertain nature, and sheer size of the $R \& D$ projects necessary to create these new energy technologies make such R\&D unprofitable for private firms. ${ }^{27}$ One way to address this in the ENTICE-BR model is to assume that the social rate of return on energy $\mathrm{R} \& \mathrm{D}$ is higher than on other R\&D. ${ }^{28}$ Thus, I re-run the model, assuming that the gap between social and private rates of return for energy $R \& D$ is eight times that of other investments, but maintain the four times gap for other R\&D. As shown in Figure 8, R\&D subsidies do play a larger role in this case, as the welfare gain of an optimal carbon tax policy nearly doubles from $\$ 2.49$ trillion without $\mathrm{R} \& \mathrm{D}$ subsidies to $\$ 4.21$ trillion when $\mathrm{R} \& \mathrm{D}$ subsidies are also included in the policy mix. Moreover, in this case subsidies alone raise welfare by $\$ 2.18$ trillion. Raising the social returns also increases the size of the optimal subsidy, as shown in Figure 7. In the near term, the largest gains are for energy efficiency subsidies, as the payoff of such gains appears more quickly with the base value of $\$ 1200$ for a starting backstop price. ${ }^{29}$ Thus, advocates of large increases in energy R\&D may be justified if they can successfully argue that the social benefits (net of any potential environmental gains) of energy $R \& D$ are truly greater than other types of R\&D. 


\subsection{OTHER CLIMATE POLICIES}

By implementing an optimal carbon tax, the above simulation shows the maximum possible gains to economic welfare from correcting the market failures concerning emissions and R\&D. However, most discussions of climate policy revolve around more restrictive policies that set fixed emissions levels. Thus, I consider the interaction of R\&D subsidies with two additional policies - one restricting emissions to 1995 levels, and a second mandating at least 10 percent of energy come from backstop sources. ${ }^{30}$ The policy mandating backstop energy retains a carbon tax as well, so that climate policies are in place even after backstop prices fall to a level where a government mandate is not needed to encourage 10\% market penetration.

Figure 9 compares atmospheric temperature under the BAU scenario and each of our three policy scenarios. For each policy scenario, results are presented for policies that also include R\&D subsidies. As before, these subsidies have little effect on the value of variables other than $R \& D$, so that the results without subsidies are similar. Requiring $10 \%$ of total energy to come from backstop sources slightly lowers atmospheric temperature in the short run, but has little long-term effect.

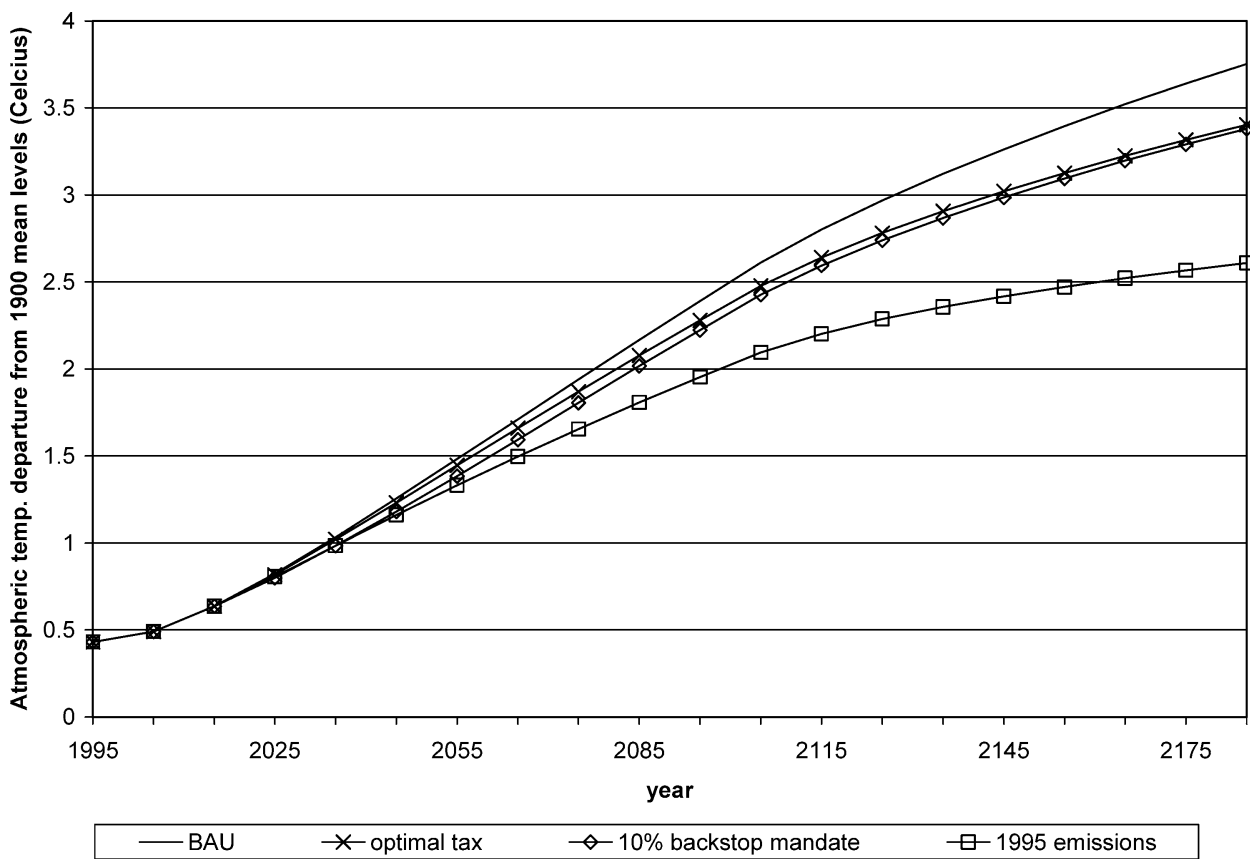

Figure 9. Temperature Under Various Policy Scenarios. The figure shows the departure of global mean temperature from 1990 levels, reported in degrees Celsius, under various policy scenarios. In each case, both emissions reduction policies and $R \& D$ subsidies are used. While the backstop mandate has little effect on long-run atmospheric temperature, restricting emissions to 1995 levels reduces long-run temperature by over one degree Celsius compared to BAU. 


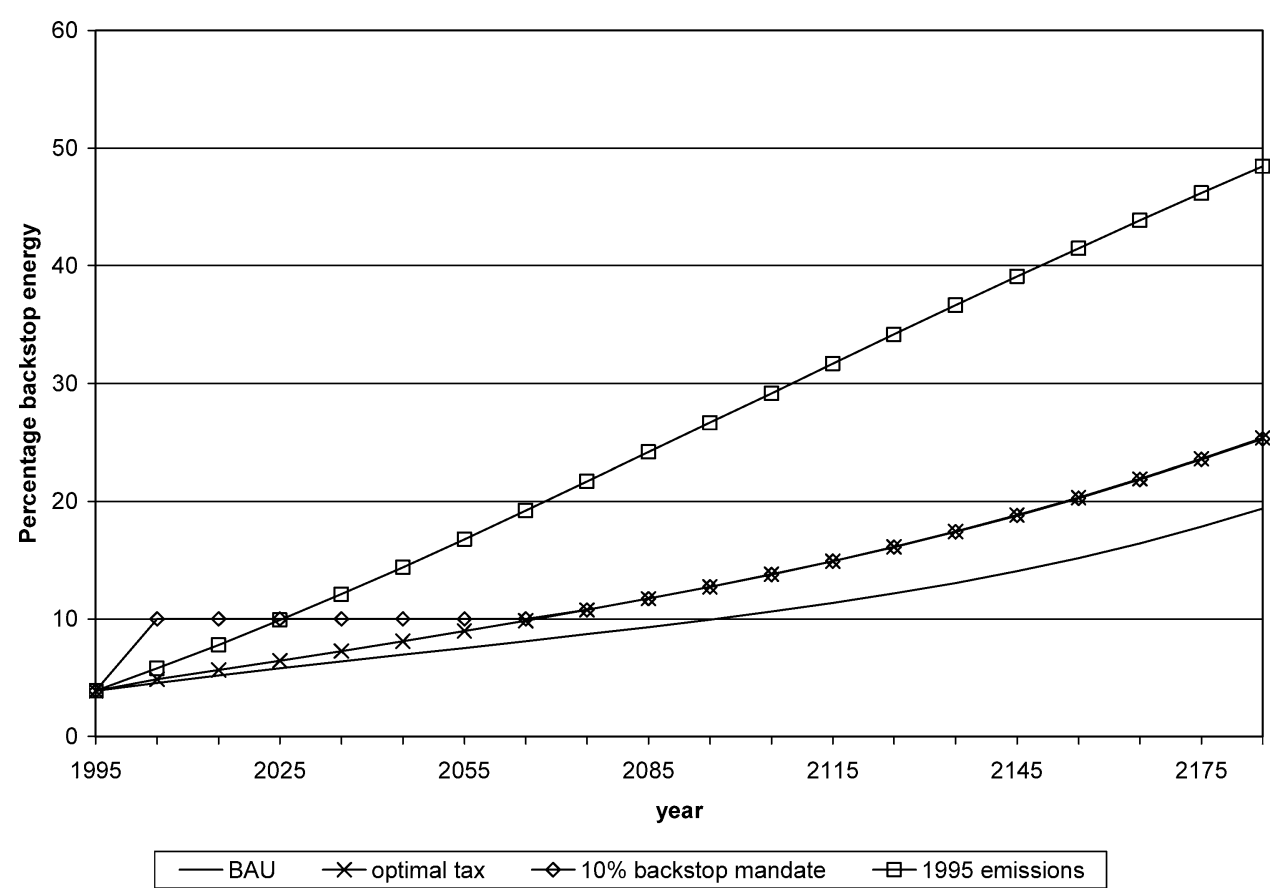

Figure 10. Percentage of Energy From Backstop Sources Under Various Policy Scenarios. The figure shows the percentage of energy from backstop sources under various policy scenarios. Note that the backstop mandate increases backstop usage in the short-run, but has little long run effect.

As shown in Figure 10, which illustrates the percentage of energy coming from backstop sources under each policy, the mandate merely speeds up the time it takes for backstop market penetration to reach $10 \%$. Once this occurs, the mandate has no additional effect, and usage patterns mirror those of the optimal carbon tax policy.

In contrast, restricting emissions to 1995 levels lowers atmospheric temperature nearly one degree Celsius more than either the optimal tax or backstop mandate policies. However, this drop in temperature comes at a cost. As shown in Table II, restricting emissions to 1995 levels has a negative impact on net economic welfare - the potential benefits of reduced emissions do not justify the costs of reducing emissions quickly. Recall from Figure 3 that an optimal climate policy entails a gradual emissions reduction. Acting quickly forces short-term reductions before technology has had a chance to evolve and lower the costs of action.

Turning to $R \& D$, note that while $R \& D$ subsidies increase both backstop and energy efficiency R\&D under these alternative polices, the impact of this additional R\&D is generally negligible. Figure 11 shows backstop and energy efficiency R\&D under each policy scenario, both with and without subsidies. Not surprisingly, the restrictive policy induces the most $\mathrm{R} \& \mathrm{D}$, particularly for backstop energy. As before, the biggest jumps in R\&D come not from environmental policy, but from the subsidies themselves. 
a. Backstop Energy $R \& D$

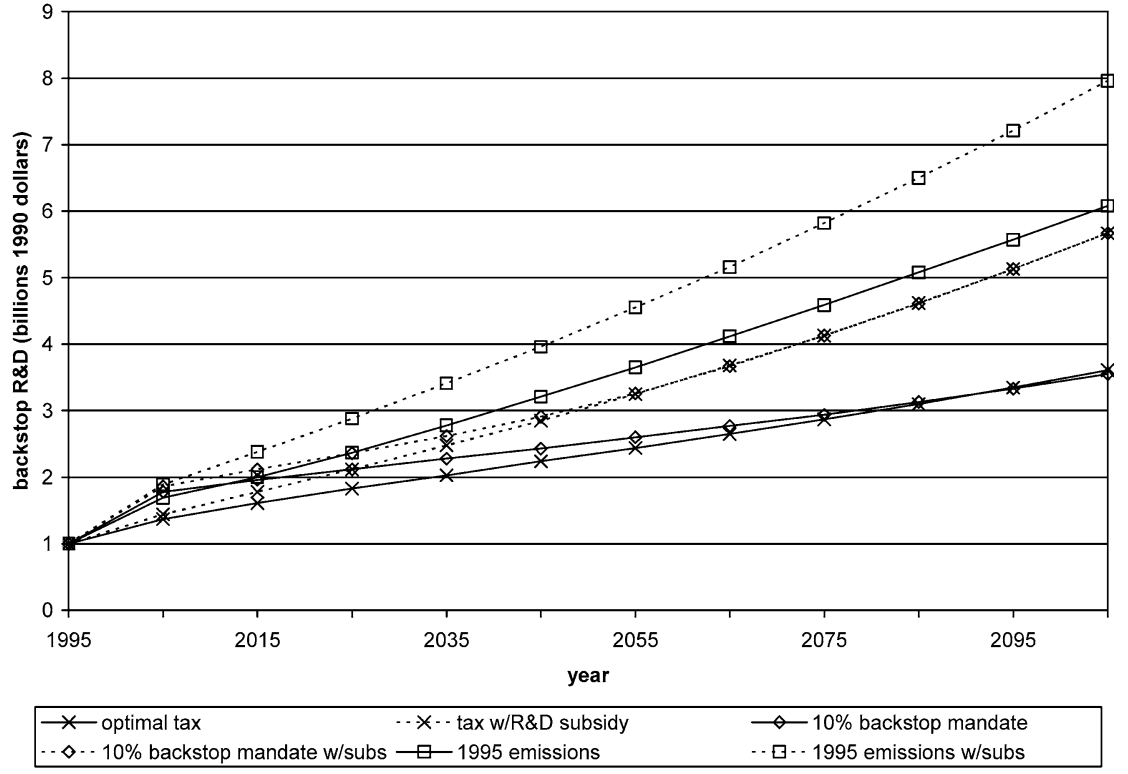

\section{b. Energy Efficiency $R \& D$}

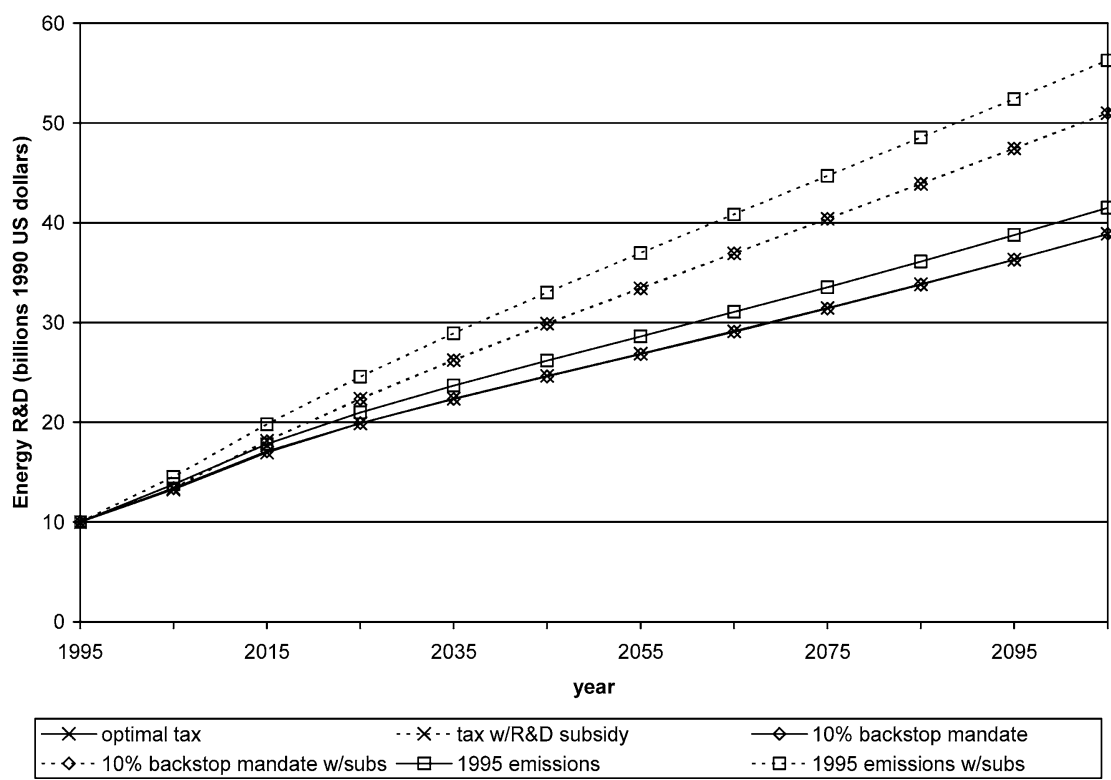

Figure 11. Energy R\&D Under Alternative Climate Policies. The figure shows the level of backstop energy R\&D (Panel A) and energy efficiency R\&D (Panel B) in billions of 1990 US dollars, under various policy scenarios. 
Nonetheless, once again R\&D subsidies have little impact on emissions or temperature. In fact, under the restricted emissions case, there is no change in temperature when R\&D subsidies are added to the policy, since the climate policy offers no incentives for reductions beyond what is initially mandated, even as subsidies improve the quality of technology. In this case, the only benefits from additional R\&D come from cost savings. Faster development of new technologies makes meeting a fixed emissions target cheaper. As a result, the carbon tax needed to meet this goal falls by 14 percent in 2005, and by five percent in 2025. Such results are consistent with the predictions of Goulder and Mathai (2000) in the case of a cost-effective policy designed to meet a given goal at the least possible cost.

However, under both the restricted emissions and backstop mandate policies, the benefits of these cost savings are small compared to the direct effect of addressing the environmental externality through policy. In each case, R\&D subsidies only improve net economic welfare by a few percentage points, as shown in Table II. Not only do R\&D subsidies not effectively address the climate change problem on their own, they also have little ability to soften the economic costs of more restrictive climate policies. ${ }^{31}$

\section{Discussion}

This paper examines the potential role that subsidies for climate-friendly R\&D may play in policy designed to reduce carbon emissions. Because firms are not fully compensated for the social benefits of knowledge spillovers, they perform less $R \& D$ than is socially optimal. $R \& D$ subsidies, either through direct government funding of $R \& D$ or through tax credits for private $R \& D$ activity, can help raise $R \& D$ levels to a socially desirable level. Indeed, the results show that such subsidies do have a significant effect on the long run levels of energy R\&D. Moreover, in the long-run subsidies induce more $R \& D$ than a carbon tax does.

However, R\&D subsidies cannot serve as a substitute for other climate policies. While R\&D levels rise dramatically when subsidies are included in the policy simulations, there is little change to other variables. Most importantly, since the subsidies do not provide incentive to adopt new technologies, emissions do not fall unless subsidies are accompanied by a policy to address the environmental externality created by carbon emissions, such as a carbon tax. Moreover, for policies designed to meet a benefit-cost criterion, using subsidies does not change the optimal level of the carbon tax, as the marginal benefits of reduced emissions do not change. In contrast, under a cost-effective criterion, designed to meet a fixed emissions target at the least possible cost, R\&D subsidies lower the tax level needed to achieve the desired emissions reductions. In both cases, while properly targeted R\&D subsidies can lower the cost of such policies somewhat, as shown by the five percent welfare gain from the policy using both a tax and subsidies in Section 3.2, the biggest gains to both welfare and the environment come from policies designed to target emissions directly. 
Finally, when setting the level of R\&D subsidies, policy makers need to consider the opportunity cost of additional R\&D. Sensitivity analysis suggests that the potential opportunity costs of $\mathrm{R} \& \mathrm{D}$ are a major limiting factor of the potential of subsidies. Because $R \& D$ requires highly trained personnel, at least some new energy R\&D efforts will likely come at the expense of other R\&D. Just as spillovers make the social returns to energy R\&D high, they also make the social returns to other types of R\&D high. Thus, some of the large social benefits of additional energy R\&D are offset by large opportunity costs from giving up other types of $R \& D$ spending. Ignoring the costs of reducing these $R \& D$ efforts would result in overly generous subsidies for energy $R \& D$, and could have negative impacts on the economy as a whole.

These results have important implications for those on both sides of the policy debate. For those who advocate that climate policy should proceed slowly, the limitations of R\&D suggest that technological change is unlikely to reduce the burden of costly climate policies by significant amounts. On the other hand, the results also offer support for those that argue that quick, strict emissions reductions are needed. For example, the go-slow approach suggested by the DICE model is partially a result of assumptions about the potential damages from climate emissions (see, for example, Kaufmann, 1997). For those who think the damages are higher, and that strict carbon policies are justified, the results show that R\&D policy alone cannot substitute for high carbon taxes or strict emissions limits if significant emissions reductions are to be achieved. Moreover, the sensitivity analysis suggests advocates of large increases in energy R\&D spending may be justified if they can show that the social returns to such R\&D truly are larger than those of other types of R\&D. Nonetheless, in any of these cases, while R\&D subsidies can be useful to lower the cost of any given emissions target, they do not eliminate the need for such a target, nor for continued debate over the stringency that emissions limits should take.

\section{Acknowledgments}

The author thanks Larry Goulder, Richard Newell, and Klaas-Jan Koops for helpful conversations that inspired this paper, and three anonymous reviewers for insightful comments on an earlier version of the paper. Financial support for this work was provided by the National Science Foundation under grant number SES-0001679.

\section{Notes}

\footnotetext{
${ }^{1}$ Even when this market failure is not addressed, there will likely exist some incentives to develop technologies that reduce carbon emissions. The market failure problem means that individuals do not consider the social benefits of using technologies that reduce emissions. However, such technologies
} 
may also come with private benefits - for example, reduced gasoline expenditures from switching to a hybrid-powered automobile.

${ }^{2}$ Intellectual property rights, such as patents, are designed to protect inventors from such copies. However, their effectiveness varies depending on the ease in which inventors may "invent around" the patent by making minor modifications to an invention. See, for example, Levin et al. (1987).

${ }^{3}$ See Popp $(2004,2005)$ for a discussion.

${ }^{4}$ As noted above, one could also endogenize technology using a learning-by-doing approach. I focus on $R \& D$ as the method of technological progress to examine the importance of the opportunity costs of such $R \& D$ spending. Because $R \& D$ investments typically have higher social returns than other investments, any new climate-friendly $R \& D$ that comes at the expense of other R\&D will come at a greater cost than R\&D that displaces other investment. Should learning-by-doing serve as a complement to $R \& D$, the costs found in this paper could be viewed as an upper bound of the costs of energy $R \& D$. While empirical work on the role of learning-by-doing versus $R \& D$ for reducing energy costs is limited, preliminary work such as Klaasen et al. (2003), Söderholm and Sundqvist (2003), and Söderholm and Klaasen (2003) suggests R\&D, rather than learning-by-doing, contributes more to cost reductions.

${ }^{5}$ Following Nordhaus and Boyer (2000), the price of one ton of carbon energy from fossil fuels is the sum of the marginal cost of carbon extraction, and a markup that captures the difference between consumer prices and the marginal costs of extraction. Defining $\mathrm{CumC}_{t}$ as cumulative carbon extraction up to year $t$, and $\mathrm{CumC}^{*}$ as the maximum possible extraction, the price of energy per ton of carbon emissions at any given time is $P_{F, t}=276.29+700\left[\mathrm{CumC}_{t} / \mathrm{Cum} \mathrm{C}^{*}\right]^{4}$.

${ }^{6}$ As in the basic DICE model, other types of R\&D are treated exogenously, and simply modeled as increases in the productivity of all inputs over time.

${ }^{7}$ Technology also enters exogenously through $\Phi_{t}$, which represents exogenous changes in the ratio of carbon emissions per unit of carbon services. Examples include changes in consumption patterns and switching to less carbon-intensive fossil fuels, such as natural gas. The role of exogenous technological change is explored more fully in Popp (2004). This remaining technological change is retained so that emissions in the baseline (no policy) simulation with $\mathrm{R} \& \mathrm{D}$ replicate the results of the DICE model without R\&D. The R\&D modeled in the ENTICE models captures purposeful shortterm efforts to improve energy efficiency or lower the costs of the backstop technology. However, such $R \& D$ is not the only way in which carbon intensity falls over time. Because the DICE model and its variants are a one-sector macroeconomic growth model, changes in consumption patterns or substitution among types of fossil fuels are not explicitly modeled. As a result, long-run emissions simulated without any exogenous decline in carbon-intensity are unrealistically high. Fortunately, Popp (2004) shows that the percentage of exogenous technological change remaining does not affect the net economic impact of induced technological change, as it is the level of R\&D induced between an exogenous and endogenous $\mathrm{R} \& \mathrm{D}$ simulation that is important. Changing the scaling factor only changes the level of emissions in each simulation, but not the difference between results in simulations with and without climate policy.

${ }^{8}$ These subsidies could be direct (e.g. government funding of R\&D) or indirect (e.g. tax credits for privately financed R\&D). As the ENTICE model is a one-sector macroeconomic model, the specific method of subsidizing R\&D is not specified. Rather, I report the increased level of R\&D that occurs after subsidies are in place. Moreover, there is no explicit government budget constraint, so that all government revenues for subsidies can be viewed as coming from non-distortionary lump-sum taxes.

${ }^{9}$ See, for example, Popp (2004) and Goolsbee (1998).

${ }^{10}$ For this paper, I assume that one-half of energy R\&D occurs at the expense of other R\&D and one-half is new $R \& D$ spending. It is only the half that occurs at the expense of other $R \& D$ that has a social cost of $\$ 4$, so that crowdout $=0.5$, as discussed in Popp (forthcoming, 2004). These papers 
show that assumptions about crowding out are important, and explain much of the variation found across climate policy models that include induced technological change.

${ }^{11}$ The appendix is available from the author at http://faculty.maxwell.syr.edu/dcpopp/research. html.

${ }^{12}$ Because the main interest of the model is to study the effect of policy-induced $R \& D$, this elasticity is calculated using differences in the carbon price with and without a carbon tax for a given year. Please see the appendix, available at http://faculty.maxwell.syr.edu/dcpopp/research.html, for more details.

${ }^{13}$ To compare these prices to existing estimates of renewable energy costs, it is useful to convert the prices to cents per kWh. Using data on total primary energy supply (IEA 1997), I calculate the energy services provided per ton of carbon emission. The initial carbon price of \$276.29 in ENTICE-BR yields a cost of energy of $1.8 \phi / \mathrm{kWh}$ (in 1990 U.S. dollars). In comparison, the backstop costs used in Popp (forthcoming) imply costs of $2.4 \phi / \mathrm{kWh}, 7.1 \phi / \mathrm{kWh}$, and $11.9 \phi / \mathrm{kWh}$. Such estimates are in the range of estimated renewable costs provided in the literature (see, for example, Table 7.25 in Goldemberg, et al. (2000).)

${ }^{14}$ Because ENTICE-BR is a global model, permit trading cannot be modeled explicitly. However, the optimal tax can also be thought of as the price of a permit that would result from an optimal allocation of permits over time.

${ }^{15}$ Of course, the implied assumption that the social rate of return on R\&D now equals that of other investments implies that the government sets subsidy levels at a socially optimal level. Thus, the results provide an upper bound for the potential of R\&D subsidies. Realistically, one would expect political constraints and imperfect information to limit the government's ability to set optimal subsidies. This strengthens the results that follow, which suggest that subsidies by themselves are not nearly as effective as carbon taxes.

${ }^{16}$ All monetary figures are presented in 1990 U.S. dollars.

${ }^{17}$ Note that the emissions profiles resulting from such a policy are higher than typically advocated by climate scientists, and do not achieve stabilization of carbon concentrations at twice those of preindustrial levels. ENTICE, and other models based on the original DICE model, use a cost-benefit framework to compare the benefits of reduced emissions to the cost of achieving these reductions. Because carbon emissions persist in the atmosphere, small changes in emissions today have little effect on long-term temperature trends. At the same time, major reductions necessary to achieve stabilization of atmospheric carbon concentrations are often seen as too costly (see, for example, the discussion in chapter 7 of Nordhaus and Boyer 2000). The slow approach suggested by the DICE model is also partially a result of assumptions about the potential damages from climate emissions (see, for example, Kaufmann 1997). Nonetheless, because stricter carbon policies are often advocated by policymakers, such policies are discussed in Section 3.4.

${ }^{18}$ To get this starting value, I begin with a total global R\&D budget of $\$ 500$ billion. In the U.S., two percent of R\&D spending in 1995 went to energy-related $R \& D$. The $\$ 10$ billion figure used in this paper is simply two percent of the global level of $R \& D$. The $\$ 1$ billion figure for backstop research represents an additional 10 percent of energy R\&D, based on data in Anderson (1997).

${ }^{19}$ Such a policy is implemented in ENTICE-BR by first solving the model with a carbon tax and no rate of return constraint. I then constrain R\&D to the levels found in that run, and re-run the model without a carbon tax.

${ }^{20}$ Note that, unlike Schneider and Goulder (1997), I only consider the effect of correcting the knowledge market failures for energy R\&D only, rather than broader policies designed to correct market failures in all R\&D markets.

${ }^{21}$ It is important to note that some of this $\$ 10$ billion already comes from government spending. Given this, the BAU R\&D spending should be thought of as $R \& D$ spending assuming that current trends continue, and the various policy simulations can be seen as deviations from these trends. Because more R\&D is publicly financed in the energy sector than in the economy as a whole, we 
would expect the deviation between private and social returns to be lower than in the general. This suggests that the results here are an upper bound of the potential of R\&D subsidies.

${ }^{22}$ The result that the carbon tax does not change is consistent of the theoretical predictions of Goulder and Mathai's (2000) benefit-cost model, which compares optimal tax levels with and without policy-induced technological change (but ignores knowledge spillovers and R\&D subsidies).

${ }^{23}$ The result follows from the combination of the social returns on R\&D being four times that of other investments, and from the assumption that $50 \%$ of new energy R\&D comes at the cost of other $R \& D$. Thus, the total social cost of new energy $R \& D$ is twice that of other investments.

${ }^{24}$ Note that, when making these adjustments to the model, small changes in other parameters (typically the $a$ parameter in equation (4)), are needed to keep initial R\&D levels at reasonable levels. The appendix, available at http://faculty.maxwell.syr.edu/dcpopp/research.html, includes the complete set of parameters used, along with the level of R\&D under the optimal policy with each set of assumptions.

${ }^{25}$ In this case, even in the BAU scenario, $29 \%$ of energy comes from the backstop by 2055 , and $64 \%$ by 2105 . With an optimal carbon tax, these figures increase to $46 \%$ and $85 \%$, respectively. See Popp (forthcoming) for a more detailed discussion of a lower backstop price on other variables.

${ }^{26}$ Popp (forthcoming) shows that increased usage of the backstop with a low initial backstop price lowers long-run atmospheric temperature by nearly a degree Celsius, even without any climate policy in place.

${ }^{27}$ For example, Hoffert et al. (2002) discuss the need for advanced technology to stabilize carbon emissions, writing that the greenhouse effect is "an energy problem that cannot simply be regulated away" (p. 986).

${ }^{28}$ Note here that the social rate of return focuses on returns valued by the market, such as lower energy costs or consumption. The additional benefits from improved environmental policy are not included, since those benefits would not be part of the firm's decision-making process on whether or not to perform energy R\&D.

${ }^{29}$ Note that the optimal policy remains to go slow, which is why an immediate spike in backstop $\mathrm{R} \& \mathrm{D}$ does not occur in the optimal policy even with the assumption of higher returns to energy $\mathrm{R} \& \mathrm{D}$.

${ }^{30}$ Popp (forthcoming) includes a discussion of a policy restricting emissions without R\&D subsidies.

${ }^{31}$ Moreover, this result is generally robust to sensitivity analysis such as presented in Section 3.3. Because these policies mandate specific levels of performance, changing parameter values does not affect outcomes such as emissions or temperature, but rather changes the costs of achieving the policy goal. As with the optimal tax policy, the role of $R \& D$ subsidies is enhanced when crowding out of other R\&D does not occur. Also, as in Popp (forthcoming), restricting emissions to 1995 levels is welfare enhancing (although not as much as is the optimal tax policy) with a low backstop price, as the carbon tax necessary to induce a switch to primarily carbon-free energy is not as large. For example, in 2055 , a tax of just $\$ 83.14$ without subsidies and $\$ 72.33$ with subsidies is sufficient to limit emissions to 1995 levels, compared to a tax of $\$ 1758.93$ with subsidies and the base parameters. See Popp (forthcoming) for a more detailed analysis.

\section{References}

Anderson, D.: 1997, 'Renewable energy technology and policy for development', Annual Review of Energy and the Environment 22, 187-215.

Bazelon, C. and Smetters, K.: 1999, 'Discounting inside the Washington beltway', Journal of Economic Perspectives 13(4), 213-228.

Buonanno, P., Carraro, C., and Galeotti, M.: 2003, 'Endogenous induced technical change and the costs of Kyoto', Resource and Energy Economics 25(1), 11-34. 
Caldeira, K., Jain, A. K., and Hoffert, M. I.: 2003, 'Climate sensitivity uncertainty and the need for energy without $\mathrm{CO}_{2}$ emission', Science 299, 2052-2054.

Fischer, C. and Newell, R.: 2004, 'Environmental and technology policies for climate change and renewable energy', Resources for the Future Discussion Paper 04-05.

Gerlagh, R. and van der Zwaan, B.: 2003, 'Gross world product and consumption in a global warming model with endogenous technological change', Resource and Energy Economics 25(1), 3557.

Geroski, P.: 1995, 'Markets for technology: Knowledge, innovation, and appropriability', in Stoneman, P. (ed.), Handbook of the Economics of Innovation and Technological Change, Blackwell Publishers, Oxford UK, pp. 90-131.

Goldemberg, J. et al. eds.: 2000, Word Energy Assessment: Energy and the Challenge of Sustainability, United Nations Development Programme, New York

Goolsbee, A.: 1998, 'Does government R\&D policy mainly benefit scientists and engineers?' American Economic Review 88(2), 299-302.

Goulder, L.H. and Mathai, K.: 2000, 'Optimal $\mathrm{CO}_{2}$ Abatement in the presence of induced technological change', Journal of Environmental Economics and Management 39(1), 1-38.

Goulder, L.H. and Schneider, S.H.: 1999, 'Induced technological change and the attractiveness of $\mathrm{CO}_{2}$ emissions abatement', Resource and Energy Economics 21(3-4), 211-253.

Grübler, A. and Messner, S.: 1998, 'Technological change and the timing of mitigation measures', Energy Economics 20(5-6), 495-512.

Hall, B.: 1996, 'The private and social returns to research and development', in Smith, B. and Barfield, C. (eds.), Technology, $R \& D$, and the Economy, Brookings, Washington, D.C., pp. 140-183.

Hoffert, M.I., Caldeira, K.,Benford, G., Criswell, D. R., Green, C., Herzog, H., Jain, A.K., Kheshgi, H.S., Lackner, K.S., Lewis, J.S., Lightfoot, H.D., Manheimer, W., Mankins, J.C., Mauel, M.E., Perkins, L.J., Schlesinger, M.E., Volk, T., and Wigley, T.M.L.: 2002, 'Advanced technology paths to global climate stability: Energy for a greenhouse planet', Science 298(1), 981-986.

Jaffe, A.B.: 1986, 'Technological opportunity and spillover of R\&D: Evidence from firms' patents, profits, and market value', American Economic Review 76, 984-1001.

Jones, C.I. and Williams, J.C.: 1998, 'Measuring the social return to R\&D', Quarterly Journal of Economics 113(4), 1119-1135.

Karshenaas, M. and Stoneman, P.: 1995, 'Technological diffusion', in Stoneman, P. (ed.), Handbook of the Economics of Innovation and Technological Change, Blackwell Publishing, Oxford, UK, pp. 265-297.

Kaufmann, R.K.: 1997, 'Assessing the DICE model: Uncertainty associated with the emission and retention of greenhouse gases', Climatic Change 35(4), 435-448.

Klaassen, G., Miketa, A., Larsen, K., and Sundqvist, T.: 2003, 'Public R\&D and innovation: The case of wind energy in Denmark, Germany, and the United Kingdom', Interim Report IR-03-011, International Institute for Applied Systems Analysis.

Kverndokk, S., Rosendahl, K.E., and Rutherford, T.F.: 2004, 'Climate policies and induced technological change: Which to choose, the carrot or the stick?' Environmental and Resource Economics 27(1), 21-41.

Levin, R.C., Klevorick, A.K. Nelson, R.R., and Winter, S.G.: 1987, 'Appropriating the returns from industrial research and development', Brookings Papers on Economic Activity 3, 783-820.

Manne, A.S. and Richels, R.G.: 2002, 'The impact of learning-by-doing on the timing and costs of $\mathrm{CO}_{2}$ abatement', Energy Economics 26(4), 603-619.

Mansfield, E.: 1996, 'Microeconomic policy and technological change', in Fuhrer, J.C. and Little, J.S. (eds.), Technology and Growth: Conference Proceedings, Federal Reserve Bank of Boston, pp. 183-200.

Mansfield, E.: 1977, 'Social and private rates of return from industrial innovations', Quarterly Journal of Economics 91, 221-240. 
Messner, S.: 1997, 'Endogenized technological learning in an energy systems model', Journal of Evolutionary Economics 7(3), 291-313.

Pakes, A.: 1985, 'On patents, R\&D, and the stock market rate of return', Journal of Political Economy 93, 390-409.

Nordhaus, W.D.: 2002, 'Modeling induced innovation in climate-change policy', in: Grübler, A., Nakicenovic, N., and Nordhaus, W.D. (eds.), Technological Change and the Environment, Resources for the Future, Washington, DC, pp. 182-209.

Nordhaus, W.D.: 1994, Managing the Global Commons: The Economics of the Greenhouse Effect, MIT Press, Cambridge, MA.

Nordhaus, W.D. and Boyer, J.: 2000, Warming the World: Economic Models of Global Warming, MIT Press, Cambridge, MA.

Popp, D.: forthcoming, 'ENTICE-BR: The effects of backstop technology R\&D on climate policy models', forthcoming in Energy Economics.

Popp, D.: 2005, 'Lessons from patents: Using patents to measure technological change in environmental models', Ecological Economics 54(2-3), 209-226.

Popp, D.: 2004, 'ENTICE: Endogenous technological change in the DICE model of global warming', Journal of Environmental Economics and Management 48(1), 742-768.

Popp, D.: 2002, 'Induced innovation and energy prices', American Economic Review 92, 160-180.

Popp, D.: 2001, 'The effect of new technology on energy consumption, Resource and Energy Economics 23(3), 215-239.

Schneider, S.H. and Goulder, L.H.: 1997, 'Achieving low-cost emissions targets', Nature 389, 13-14.

Söderholm, P. and Klaassen, G.: 2003, 'Wind power in europe: A simultaneous innovation-diffusion model', paper presented at the 12th Annual Conference of the European Association of Environmental and Resource Economists, Bilbao, Spain, June 28-30, 2003.

Söderholm, P. and Sundqvist, T.: 2003, 'Learning curve analysis for energy technologies: Theoretical and econometric issues', paper presented at the Annual Meeting of the International Energy Workshop (IEW), Laxenburg, Austria, June 2003.

van der Zwaan, B.C.C., Gerlagh, R., Klaassen, G., and Schrattenholzer, L.: 2002, 'Endogenous technological change in climate change modeling', Energy Economics 24(1), 1-19.

Wigley, T.M., Richels, R.G., and Edmonds, J.A.: 1996, 'Economic and environmental choices in the stabilization of atmospheric $\mathrm{CO}_{2}$ concentrations', Nature 379, 240-243.

(Received 2 September 2004; in revised form 28 November 2005) 